\title{
Intercomparison of stratospheric ozone and temperature profiles during the October 2005 Hohenpeißenberg Ozone Profiling Experiment (HOPE)
}

\author{
W. Steinbrecht ${ }^{1}$, T. J. McGee ${ }^{2}$, L. W. Twigg ${ }^{2}$, H. Claude ${ }^{1}$, F. Schönenborn ${ }^{1}$, G. K. Sumnicht ${ }^{2}$, and D. Silbert ${ }^{2}$ \\ ${ }^{1}$ Meteorologisches Observatorium, Deutscher Wetterdienst, Hohenpeißenberg, Germany \\ ${ }^{2}$ NASA Goddard Space Flight Center, Greenbelt MD, USA
}

Received: 5 November 2008 - Published in Atmos. Meas. Tech. Discuss.: 12 January 2009

Revised: 9 April 2009 - Accepted: 21 April 2009 - Published: 27 April 2009

\begin{abstract}
Thirteen clear nights in October 2005 allowed successful intercomparison of the lidar operated since 1987 by the German Weather Service (DWD) at Hohenpeißenberg $\left(47.8^{\circ} \mathrm{N}, 11.0^{\circ} \mathrm{E}\right)$ with the Network for the Detection of Atmospheric Composition Change (NDACC) travelling standard lidar operated by NASA's Goddard Space Flight Center. Both lidars provide ozone profiles in the stratosphere, and temperature profiles in the strato- and mesosphere. Additional ozone profiles came from on-site Brewer/Mast ozonesondes, additional temperature profiles from Vaisala RS92 radiosondes launched at Munich (65 km north-east), and from operational analyses by the US National Centers for Environmental Prediction (NCEP).

The intercomparison confirmed a low bias for ozone from the DWD lidar in the 33 to $43 \mathrm{~km}$ region, by up to $10 \%$. This bias is caused by the DWD ozone algorithm, and is consistent with previous comparisons of the DWD lidar with SAGE, GOMOS and other instruments. During HOPE, precision (repeatability) for ozone data from both lidars was better than $5 \%$ between 20 and $40 \mathrm{~km}$ altitude, dropping to $10 \%$ near $45 \mathrm{~km}$, and to $50 \%$ near $50 \mathrm{~km}$. These results are consistent with previous NDACC intercomparisons, and confirm the reliability of the NASA NDACC travelling standard lidar.

Temperature from the DWD lidar showed a 1 to $2 \mathrm{~K}$ cold bias from 30 to $65 \mathrm{~km}$ against the NASA lidar, and a 2 to $4 \mathrm{~K}$ cold bias against radiosondes and NCEP. This is also consistent with previous intercomparisons. Temperature precision
\end{abstract}

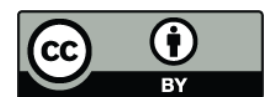

Correspondence to: $\mathrm{W}$. Steinbrecht (wolfgang.steinbrecht@dwd.de) (repeatability) for the DWD lidar was better than $2 \mathrm{~K}$ from 30 to $50 \mathrm{~km}$, decreasing to $10 \mathrm{~K}$ near $70 \mathrm{~km}$. For the NASA lidar, precision is expected to be better than $1 \mathrm{~K}$ over the 30 to $70 \mathrm{~km}$ range. However, due to the much lower temperature precision of the DWD lidar, this could not be checked during HOPE. It was noted that the current DWD algorithm overestimates temperature uncertainty, which should be reduced by a factor of 2.2 (e.g. from $22 \mathrm{~K}$ to $10 \mathrm{~K}$ near $70 \mathrm{~km}$ ).

The HOPE intercomparison did uncover a $290 \mathrm{~m}$ range error (upward shift) of the DWD lidar data. When this shift is removed, the bias of the ozone algorithm is corrected, and a better background estimation is used, ozone profiles from the DWD lidar agree very well with both the NASA lidar and SAGE. Systematic differences are then smaller than $3 \%$ between 20 and $44 \mathrm{~km}$, and smaller than $5 \%$ between 17 and $47 \mathrm{~km}$. These differences are close to zero, and are not (statistically) significant. The cold temperature bias against the NASA lidar also disappears when the DWD temperature processing is corrected for the $290 \mathrm{~m}$ range error, and more appropriate values for the Earth's gravity acceleration are used. Compared to the radiosondes or NCEP analyses, however, both lidars show 1 to $2 \mathrm{~K}$ lower temperatures over the entire 15 to $35 \mathrm{~km}$ range.

Temperature and ozone variations are tracked well by both lidars, by ozone- and radiosondes, and by NCEP analyses. Correlations exceed 0.8 to 0.9 at most stratospheric levels. They decrease at levels above $40 \mathrm{~km}$, especially for ozone or NCEP temperature.

The ozone and temperature bias of the DWD lidar does not appear to have changed over time. Records of ozone and temperature from the DWD lidar should be consistent over

Published by Copernicus Publications on behalf of the European Geosciences Union. 
the years. Nevertheless, the HOPE intercomparison was instrumental in uncovering and repairing several long-standing errors. HOPE also confirmed the reliability of the NASA lidar as a travelling standard. Now the entire DWD lidar data record needs to be reprocessed with the improved and revised algorithms.

\section{Introduction}

In 1990, the International Network for the Detection of Stratospheric Change (NDSC, http://www.ndsc.ncep.noaa. gov) was formed to provide a consistent, standardized set of long-term measurements of stratospheric trace gases, particles, and physical parameters via a suite of globally distributed sites. Within the NDSC, which was expanded and renamed Network for the Detection of Atmospheric Composition Change (NDACC) in 2006, lidars (=laser radars) are key instruments for measuring the stratospheric ozone and temperature profile. Lidar measurements of ozone and temperature are self-calibrating, in principle (e.g., Hauchecorne and Chanin, 1980; Megie et al., 1985; Carswell et al., 1991). This makes them especially suited for long-term monitoring.

An important aspect of NDACC are dedicated instrument intercomparison campaigns, where several instruments are co-located to measure in close spatial and temporal vicinity for an intensive period of days to weeks. Examples are the 1989 Stratospheric Ozone Intercomparison Campaign at Table Mountain (Margitan et al., 1995), the 1995 Ozone Profiler Assessment at Lauder (McDermid et al., 1998a, b), or the 1997 intercomparison at Haute Provence (Braathen et al., 2004). Keckhut et al. (2004) give an overview of ozone and temperature lidar validations performed within the NDACC framework.

In most NDACC lidar intercomparisons, the mobile lidar operated by NASA's Goddard Space Flight Center (NASAGSFC) has served as the travelling standard. While the first intercomparisons resulted in major hardware and software improvements (McGee et al., 1991, 1993, 1995a), the configuration of the NASA lidar has been very stable and mature since about 1995. Comparisons of the NASA lidar at Haute Provence (Braathen et al., 2004), Mauna Loa (McPeters et al., 1999), and Lauder (McDermid et al., 1998a, b) have shown that it measures ozone profiles with less than $5 \%$ bias between 15 and $45 \mathrm{~km}$ altitude, and with less than $3 \%$ bias between 20 and $40 \mathrm{~km}$ (see also Tsou et al., 2000; Keckhut et al., 2004). Precision (repeatability) is typically better than $3 \%$ between 20 and $40 \mathrm{~km}$, dropping to $10 \%$ at 15 or $45 \mathrm{~km}$, and to $50 \%$ near $50 \mathrm{~km}$.

The initial validation of temperature profiles from the NASA lidar is discussed in Ferrare et al. (1995), Singh et al. (1996), and Gross et al. (1997). Temperature has been more difficult to assess, because there are not as many reliable instruments available as for ozone, and because atmo- spheric tides lead to important variability. Also an accuracy of $2 \%$ would be good for ozone, but $2 \%$ for temperature corresponds to an accuracy of 5 to $6 \mathrm{~K}$ only. In general, the intercomparisons of the NASA lidar have demonstrated a temperature accuracy at the 1 to $2 \%$ level, i.e. better than 2 to $5 \mathrm{~K}$ over the 20 to $70 \mathrm{~km}$ altitude range. Temperature precision (repeatability) is better than $1 \mathrm{~K}$ between 20 and $50 \mathrm{~km}$, dropping to $3 \mathrm{~K}$ near $70 \mathrm{~km}$ (see also Keckhut et al., 2004).

The stationary lidar at Hohenpeißenberg $\left(47.8^{\circ} \mathrm{N}\right.$, $11.0^{\circ} \mathrm{E}$ ) has been operated since September 1987 by the German Weather Service (DWD). It has undergone only very few modifications over the years (Geh, 1987; Claude et al., 1994; Steinbrecht et al., 1997), most notably a change of the photon-counters in January 1995, and a change of the interference filters in November 1998. The DWD lidar has provided one of the longer NDACC time series, but has so far not participated in a formal NDACC on-site intercomparison. Intercomparisons with local ozonesondes, and satellite measurements, however, have been done on many occasions (Steinbrecht et al., 1997, 2006). Details of both lidars are given in Table 1 and in Sect. 2.

In October 2005, the mobile NASA-GSFC lidar was finally deployed at Hohenpeißenberg for intercomparison in the Hohenpeißenberg Ozone Profiling Experiment (HOPE). Section 3 of this paper gives an overview of the campaign and the main data sources. The HOPE intercomparison was initially carried out as an NDACC "blind" intercomparison. Within a few days of the measurement, ozone and temperature profiles from both lidars were submitted to an independent referee (R. Neuber from the Alfred-Wegener-Institute in Potsdam, Germany). Each group was not allowed to see results from the other group, but was allowed to use their standard ancillary data, i.e. temperature profiles from nearby radiosondes, or from meteorological analyses. The comparison of these "blind" profiles is discussed in Sect. 4.

In a later, second phase, however, the NASA and DWD groups exchanged ozone and temperature profiles, as well as their lidar return signals. This allowed a more detailed error analysis, and has resulted in important improvements for the DWD ozone and temperature processing. Corrected ozone and temperature profiles from the DWD lidar show much better agreement with the other instruments. These improvements are discussed in Sect. 5, at the end of this paper.

\section{Lidar hardware, principle, and processing}

While Table 1 summarizes the main characteristics of both lidar systems, Fig. 1 gives a schematic of the DWD lidar at Hohenpeißenberg. A Xenon Chloride excimer laser generates pulses of intense ultraviolet radiation at $308 \mathrm{~nm}$. These are focused into a Raman cell, filled with pure hydrogen. Near the focus, stimulated Raman scattering by the hydrogen molecules generates a light pulse at $353 \mathrm{~nm}$ (and other wavelengths), which travels simultaneously and in the same 
Table 1. Main characteristics of the NASA Goddard Space Flight Center Stratospheric Ozone Lidar in Trailer Experiment (308 and $355 \mathrm{~nm}$ channels only), and of the DWD ozone lidar at Hohenpeißenberg.

\begin{tabular}{|c|c|c|}
\hline & NASA & DWD \\
\hline \multicolumn{3}{|l|}{ Transmitter } \\
\hline$\lambda_{\text {on }} / \lambda_{\text {off }}$ & $308 / 355 \mathrm{~nm}$ & $308 / 353 \mathrm{~nm}$ \\
\hline Laser@ $\lambda_{\text {on }}$ & Lambda Physik LPX 320 & Lambda Physik LPX 220i \\
\hline Light source @ $\lambda_{\text {off }}$ & Spectra Physics & $\mathrm{H}_{2}$ Raman Cell \\
\hline & Quanta Ray PIV-400 Nd:YAG×3 & \\
\hline transmitted pulse energy @ $\lambda_{\text {on }} / \lambda_{\text {off }}$ & $300 \mathrm{~mJ} / 150 \mathrm{~mJ}$ & $100 \mathrm{~mJ} / 10 \mathrm{~mJ}$ \\
\hline \multicolumn{3}{|l|}{ Receiver Telescope } \\
\hline telescope setup & Dall-Kirkham & Newtonian \\
\hline mirror diameter & $0.76 \mathrm{~m}$ & $0.6 \mathrm{~m}$ \\
\hline field of view & $2.3 \mathrm{mrad}$ & $0.4 \mathrm{mrad}$ \\
\hline focal length & $3.66 \mathrm{~m}$ & $2.4 \mathrm{~m}$ \\
\hline dist. receiver axis to transmitter axis & $0.75 \mathrm{~m}$ & $0.7 \mathrm{~m}$ \\
\hline receiver channels & $308 \mathrm{~nm}(\mathrm{HI}+\mathrm{LOW}), 355 \mathrm{~nm}(\mathrm{HI}+\mathrm{LOW})$ & 308 and $353 \mathrm{~nm}$ \\
\hline & $332 \mathrm{~nm}, 387 \mathrm{~nm}(\mathrm{HI}+\mathrm{LOW}), 407 \mathrm{~nm}$ & \\
\hline \multicolumn{3}{|l|}{ Interference Filters } \\
\hline manufacturer & Barr Associates & Barr Associates \\
\hline peak transmission @ $\lambda_{\text {on }} / \lambda_{\text {off }}$ & $73 / 52 \%$ & $\begin{array}{l}50 / 65 \% \\
\text { (before } 11 / 9830 / 25 \% \text { ) }\end{array}$ \\
\hline width (FWHM) @ $\lambda_{\text {on }} / \lambda_{\text {off }}$ & $1.1 / 0.92 \mathrm{~nm}$ & $\begin{array}{l}\text { 5/2 nm } \\
\text { (before October 1998: 10/2.5 nm) }\end{array}$ \\
\hline \multicolumn{3}{|l|}{ Photon Counting } \\
\hline photomultipliers & Hamamatsu 7400 P-03 & EMI 9893QA/350 \\
\hline maximum used count rate $@ \lambda_{\text {on }} / \lambda_{\text {off }}$ & $10 / 40 \mathrm{MHz}$ & $6 / 2 \mathrm{MHz}$ \\
\hline $\begin{array}{l}\text { signal induced noise } @ \lambda_{\text {on }} / \lambda_{\text {off }} \\
\text { (near } 50 \mathrm{~km} \text { ) }\end{array}$ & $\approx 500 \mathrm{~Hz} /<20 \mathrm{~Hz}$ & $<3 \mathrm{~Hz} /<0.3 \mathrm{~Hz}$ \\
\hline SIN decay time constant $@ \lambda_{\text {on }} / \lambda_{\text {off }}$ & $\approx 50 \mathrm{~km} />1000 \mathrm{~km}$ & $\approx 1000 \mathrm{~km} / \gg 1000 \mathrm{~km}$ \\
\hline $\mathrm{HV}$ range gating & all channels & - none - \\
\hline bowtie chopper & 308 nm HI channel & both channels \\
\hline multichannel scalers & LICEL $300 \mathrm{MHz}$ & $\begin{array}{l}\text { Optech FDC } 700 \\
\text { (before February 1995: LeCroy 3521) }\end{array}$ \\
\hline
\end{tabular}

direction as the original $308 \mathrm{~nm}$ pulse (e.g., Werner et al., 1983). Both pulses pass through a beam expanding telescope (10x expansion) and are transmitted vertically up into the atmosphere. A small fraction of the light is scattered back by air molecules in the atmosphere. This returned light is collected by the large primary mirror of the receiver. Inside the receiver's detector unit, a dichroic mirror separates the two emitted wavelengths. Narrowband interference filters reject skylight and the unwanted opposite wavelength. Returned photons are then detected by two photomultipliers $\left(\mathrm{PM}_{1}, \mathrm{PM}_{2}\right)$ in photon counting mode. Discriminators separate noise from true photon pulses and multichannel scalers count the returned photons (=pulses) as a function of time (=range).

The conceptual setup of the NASA lidar is similar (McGee et al., 1995a). However, instead of a Raman cell, the NASA lidar uses a second laser to generate pulses at $355 \mathrm{~nm}$ (Nd:YAG 3rd harmonic). Also, instead of 2 detector channels only $\left(\mathrm{PM}_{1}, \mathrm{PM}_{2}\right)$, the NASA lidar uses 8 detector channels. This allows simultaneous recording of return signals at 308 and $355 \mathrm{~nm}$, with full intensity, and with intensity reduced by a grey filter (=HI and LOW channels), as well as recording of return signals from vibrational Raman scattering by nitrogen $(332 \mathrm{~nm}, 387 \mathrm{~nm}$ with $\mathrm{HI}$ and LOW chan-

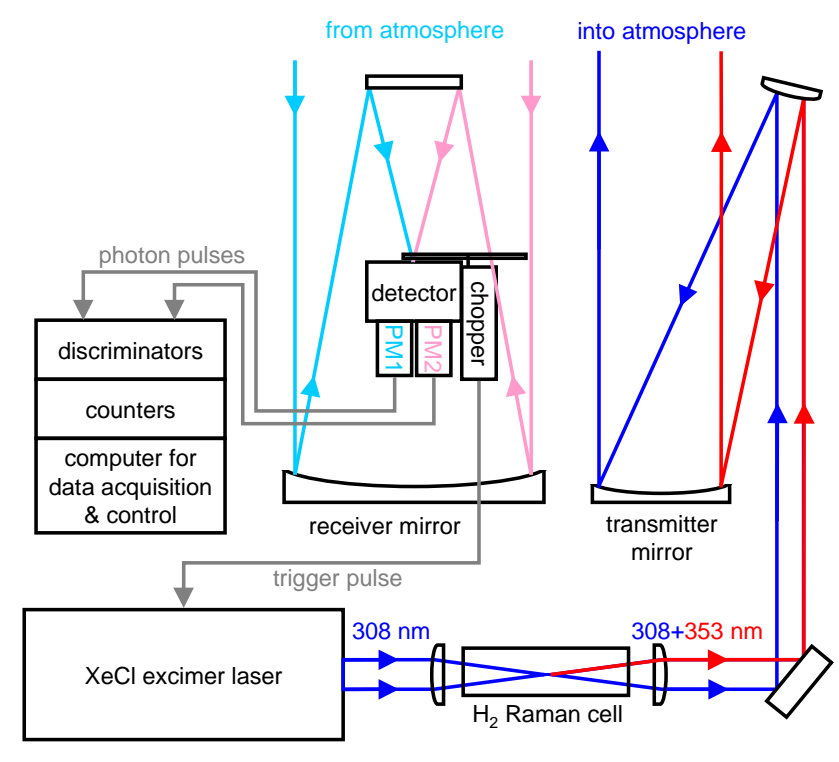

Fig. 1. Schematic of the DWD lidar system at Hohenpeißenberg (47.8 $\mathrm{N}, 11.0^{\circ} \mathrm{E}, 976 \mathrm{~m}$ a.s.1.). $\mathrm{PM}_{1}, \mathrm{PM}_{2}=$ photomultipliers for 308 and $353 \mathrm{~nm}$. 


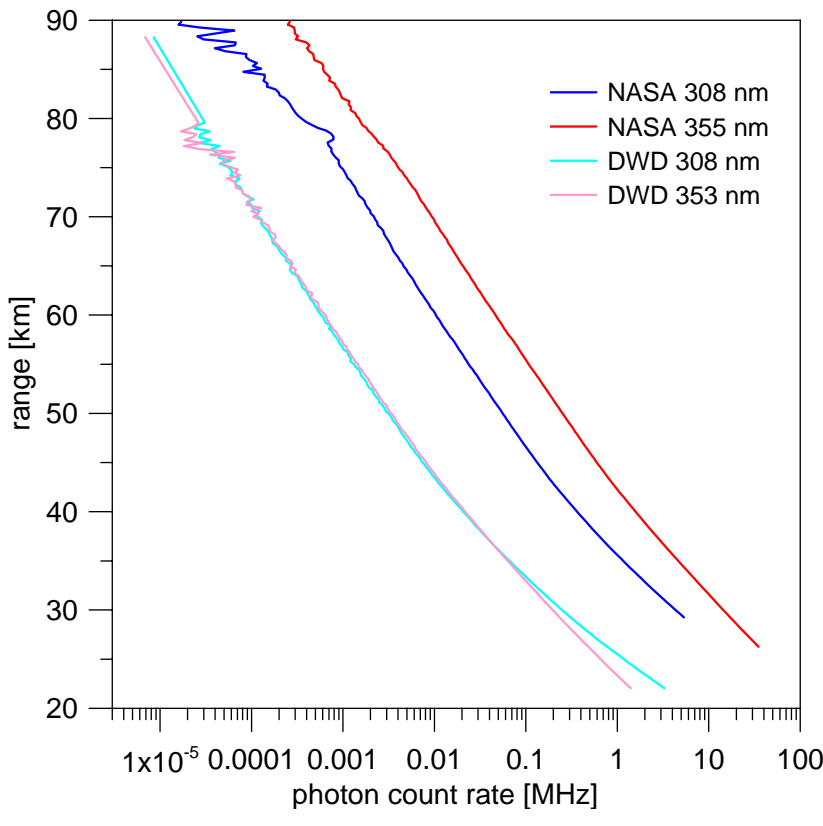

Fig. 2. Average return signals for NASA and DWD lidar for the night of 27 to 28 October 2005, from 18:18 to 03:59 UT, and from 19:25 to 04:21 UT, respectively. Only the high-range signals are shown. NASA lidar uses $15 \mathrm{~m}$ range bins, which are summed here to give $300 \mathrm{~m}$ range bins. The DWD lidar uses $300 \mathrm{~m}$ range bins below $80 \mathrm{~km}$, and $17 \mathrm{~km}$ bins above $80 \mathrm{~km}$, to reduce photon count noise. The peak in the NASA $308 \mathrm{~nm}$ return signal near $78 \mathrm{~km}$ is caused by resonance scattering from the mesospheric $\mathrm{OH}$-layer (Brinksma et al., 1998). The different slopes of the blue and red lines between 20 and $35 \mathrm{~km}$ are due to ozone absorption.

nels), plus return signals from vibrational Raman scattering by water vapour $(407 \mathrm{~nm})$. As mentioned, the NASA system has been upgraded several times since its beginnings in 1990, but over the last 10 years no major changes have been made. The DWD system has intentionally been kept close to the original configuration from 1987.

An important component of both lidars is the mechanical chopper. Its blade is rotating at high speed across the beam path in the receiver. Laser pulses are synchronized to this chopper blade, so that the very intensive return signal from low altitudes (=early times) is blocked (Werner et al., 1983; Geh, 1987; Steinbrecht et al., 1989). The chopper is crucial to avoid photomultiplier overload and unwanted after effects like signal induced noise (Iikura et al., 1987; Williamson and Young, 2000). Signal induced noise, a slowly decaying background component, can become a problem at the far range end of lidar signals (McDermid et al., 1990). A mechanical chopper greatly reduces this problem (McGee et al., 1995a). The NASA system additionally uses electronic range gating. Remaining signal induced noise is then very small, less than $1 \%$ of the signal near $50 \mathrm{~km}$ (compare 1 and Fig. 2). If not accounted for correctly, however, it can still affect ozone profiles above $40 \mathrm{~km}$, and temperature profiles above $60 \mathrm{~km}$.
Typical atmospheric return signals are given in Fig. 2, for the night of 27 to 28 October 2005. In this night, the NASA lidar measured from 18:18 to 03:59 UT, the DWD lidar from 19:25 to 04:21 UT. The DWD lidar uses $300 \mathrm{~m}$ range bins below $80 \mathrm{~km}$ and $17 \mathrm{~km}$ range bins above. The NASA lidar uses $15 \mathrm{~m}$ range bins, but for the plot in Fig. 2 these have been summed to $300 \mathrm{~m}$ range bins. Noteworthy in Fig. 2 are the high dynamic range, more than 5 orders of magnitude, and the low number of photons counted at high altitudes. At $70 \mathrm{~km}$, for example, the DWD system photon count rate is only about $100 \mathrm{~Hz}$, i.e. only 1 photon is counted every 10000 laser shots in a $1 \mu \mathrm{s}(=150 \mathrm{~m})$ range interval. The much higher count rates of the NASA lidar show the benefits of a larger receiver mirror, more powerful lasers, better photomultipliers, and other technical improvements.

Note that at count rates higher than 1 to $10 \mathrm{MHz}$ pulsepileup can lead to substantial non-linearity in the relation between returned light and counted photons (Donovan et al., 1993). Both lidar systems use corrections to account for this. In addition, both lidars use grey filters, either in separate receiver channels or in different acquisition steps, to record signals with reduced count rates. In this way, different altitude regions of the atmosphere are recorded separately, and counter saturation effects are minimized. In practice, they do not affect the ozone and temperature measurements from both lidars.

The lidar return signal $P_{\text {off }}$ at $353 \mathrm{~nm}$ (or $355 \mathrm{~nm}$ ) is not absorbed significantly by ozone. However, it contains information about the atmospheric density and temperature profiles. The return signal $P_{\text {on }}$ at $308 \mathrm{~nm}$ behaves similar, but is strongly absorbed by ozone (absorption cross-section $\sigma_{\mathrm{O}_{3}}$ ). The absorption leads to the more rapid decay of the $308 \mathrm{~nm}$ signals with altitude $z$. In Fig. 2 this is seen best for the DWD return signals near $25 \mathrm{~km}$. Essentially, comparison of the slopes of the logarithm of the return signals at 308 and $353 \mathrm{~nm}, P_{\mathrm{on}}(z)$ and $P_{\mathrm{off}}(z)$ (blue and red lines in Fig. 2), gives the ozone number density profile $n_{\mathrm{O}_{3}}(z)$ (e.g., Megie et al., 1985; Carswell et al., 1991; Steinbrecht and Carswell, 1995):

$n_{\mathrm{O}_{3}}(z)=\frac{1}{2 \sigma_{\mathrm{O}_{3}}} \frac{d}{d z} \ln \frac{P_{\mathrm{off}}(z)}{P_{\mathrm{on}}(z)}$

Numerical calculation of the derivative $d / d z$ in Eq. (1) becomes problematic at high altitudes, where the return signals are noisy (statistical noise due to the few counted photons). Taking the derivative then tends to result in very noisy ozone profiles. To reduce this problem, derivative filters in ozone processing algorithms use information from many range bins:

$\frac{d f}{d z}\left(z_{0}\right)=\sum_{i=-k}^{k} w(i) f\left(z_{i}\right)$ 


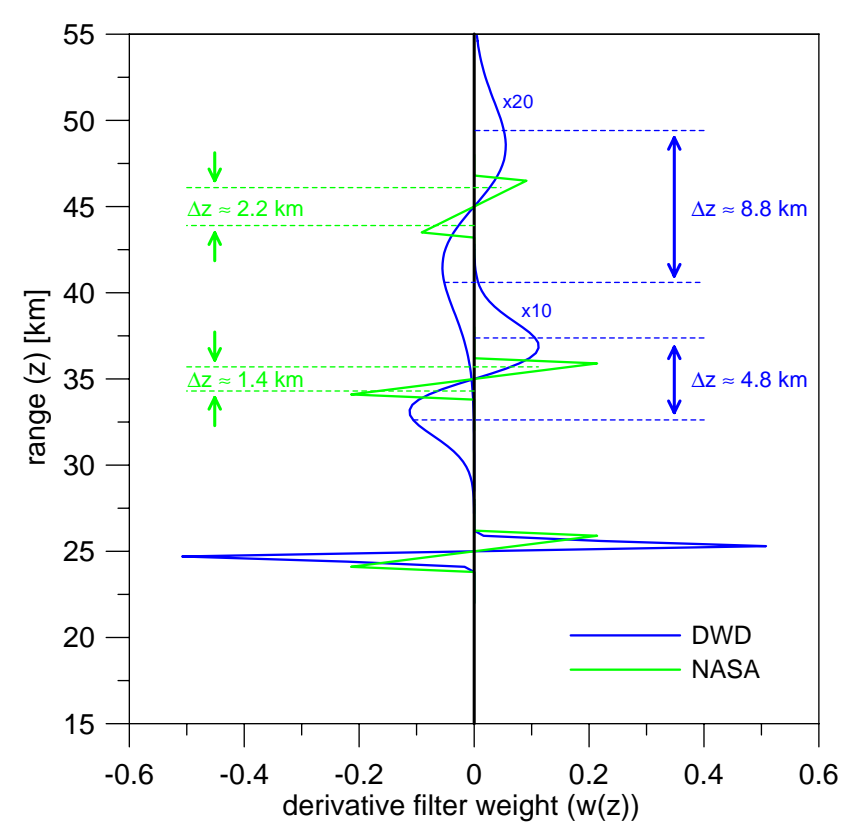

Fig. 3. Derivative filter weights $w(i)$ for DWD (blue line) and NASA (green line) ozone processing algorithms at 25, 35 and $45 \mathrm{~km}$ altitude (above the lidar). For clarity, the DWD filter weights at 35 and $45 \mathrm{~km}$ have been multiplied by 10 and 20 . At 35 and $45 \mathrm{~km}$, the distance between the dashed lines gives the effective width $\Delta z$ of the filters, as defined in Eq. (3). The effective width at $25 \mathrm{~km}$ is not shown, but is $0.8 \mathrm{~km}$ and $1.4 \mathrm{~km}$ for DWD and NASA processing, respectively.

Choosing width $k$ and weights $w(i)$ of a derivative filter always requires a trade-off between low noise and coarse range resolution (large $k$ ), or high noise and fine range resolution (small $k$ ). The choice depends on the characteristics of the specific lidar system, and on the scientific objectives of the measurements. Historically, the different NDACC lidar groups have chosen different derivative filters and have developed their own processing algorithms (see Godin et al., 1999 , for an intercomparison). Nearly all groups use a narrow filter with fine range resolution at lower altitudes, where photon counts are high, and wider filters with coarse range resolution at high altitudes, where photon counts are low. A wider filter (large $k$ ) uses more altitude channels, thus more counted photons. This reduces statistical noise. For three selected altitude levels, Fig. 3 shows the derivative filters $w(i)$ for the DWD and NASA ozone processing algorithms. Near $25 \mathrm{~km}$ altitude, both algorithms use similar filter widths, and filter shapes are comparable. At 35 and $45 \mathrm{~km}$, however, the DWD derivative filter is much wider and also has a clearly different shape from the NASA filter. The DWD algorithm is equivalent to first smoothing $f(z)$ with a Gaussian, and then taking the slope between the two points above and below the desired altitude $z_{0}$ (Steinbrecht et al., 1997). The NASA derivative filter is implemented by fitting a straight line (linear ramp) to $f(z)$, in a given window (1st or 2nd order Sav-

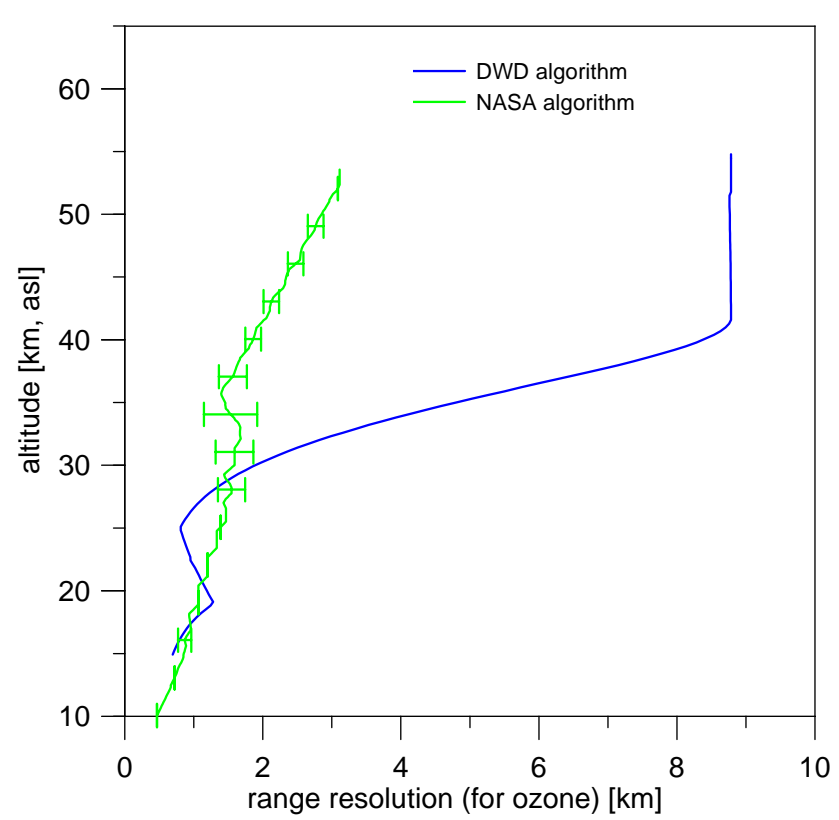

Fig. 4. Range resolution $\Delta z$ of the derivative filters $w(z)$ for NASA and DWD ozone processing algorithms. NASA adapts the range resolution individually to the return signals of each night. Therefore, standard deviation ( $1 \sigma$ error bars) and average range resolution are plotted for the NASA algorithm. The DWD range resolution is the same for every night.

itzky Golay filter, e.g., Press et al., 1992). The width of this window is increased with increasing altitude. The slope of the fitted line gives the derivative $d f(z) / d z$.

A simple way to define the range resolution $\Delta z$ for a derivative filter $w(i)$ is to use the distance between the "center" of the positive and negative lobes of the derivative filter at $z_{0}$ (compare Fig. 3).

$\Delta z=\frac{\sum_{i=-k}^{k} w(i)\left(z_{i}-z_{0}\right)}{\sum_{i=-k}^{k}|w(i)|}$

The resulting range resolutions $\Delta z$ for the filters at 35 and $45 \mathrm{~km}$ are indicated by the dashed lines in Fig. 3 .

The change of the range resolution $\Delta z$ (defined by Eq. (3)) with altitude is shown in Fig. 4 for the NASA and DWD ozone processing algorithms. Below $30 \mathrm{~km}$ altitude, both algorithms have similar fine range resolution, between 0.5 and $1.5 \mathrm{~km}$. Above $25 \mathrm{~km}$, however, the range resolution for the DWD algorithm becomes coarser very fast, changing from $1.5 \mathrm{~km}$ near $30 \mathrm{~km}$ to almost $9 \mathrm{~km}$ near $40 \mathrm{~km}$. For the NASA algorithm, the increase is smaller and more gradual, from $1.5 \mathrm{~km}$ near $30 \mathrm{~km}$ to $3 \mathrm{~km}$ near $50 \mathrm{~km}$ altitude. The much coarser range resolution of the DWD ozone algorithm is used to counteract the much lower photon count rates of this system (compare Fig. 2).

In order to derive the temperature profile, NASA and DWD processing both follow the method of Hauchecorne 
and Chanin (1980). Above the stratospheric aerosol layer, i.e. above about $30 \mathrm{~km}$, the unabsorbed return signal $P_{\text {off }}(z)$ (at 353 or $355 \mathrm{~nm})$ is proportional to molecular density $n_{\text {air }}(z)$ :

$n_{\text {air }}(z) \propto P_{\text {off }}(z) z^{2}$

Assuming hydrostatic equilibrium, and given the acceleration by Earth's gravity $g(z)$, as well as the mean molecular mass of air $M$, the relative density profile $n_{\text {air }}(z)$, provided by the lidar return signal $P_{\text {off }}(z)$, can be integrated downward. This gives the relative pressure profile $p(z)$.

$p(z)=p\left(z_{0}\right)+\int_{z}^{z_{0}} n_{\text {air }}(z) g(z) M d z$

Division of relative pressure and density then yield the temperature profile $T(z)$. The downward integration requires an initial guess for $p\left(z_{0}\right)$ or $T\left(z_{0}\right)$ at the far range limit $z_{0}$ of the lidar return signal, usually around $80 \mathrm{~km}$ for the DWD lidar, above $90 \mathrm{~km}$ for the NASA lidar. Both algorithms use the CIRA 1986 climatology (Rees et al., 1990) to provide this initial guess. With decreasing altitude below the initialization altitude, the error made by assuming a climatological temperature or pressure decreases exponentially. At $10 \mathrm{~km}$ below initialization altitude, the error is typically less than $1 \mathrm{~K}$, at $25 \mathrm{~km}$ below initialization altitude it is less than $0.1 \mathrm{~K}$ (e.g., Hauchecorne and Chanin, 1980; Steinbrecht, 1994; Leblanc et al., 1998).

Note that the temperature measurement using Eqs. (4) and (5) requires a correction for the atmospheric two-way transmission between ranges $z$ and $z_{0}$. At the 353 and $355 \mathrm{~nm}$ wavelengths used by the two lidars here, extinction by Rayleigh scattering is the dominating factor reducing the atmospheric transmission. If Rayleigh extinction was neglected completely, the lidar derived temperature would come out too low, by about $0.5 \mathrm{~K}$ near $40 \mathrm{~km}$, by about $1.5 \mathrm{~K}$ near $30 \mathrm{~km}$, and by more below. However, even with a moderately accurate density profile, the transmission effect is easily corrected in the operational algorithms. Remaining temperature errors are well below $0.1 \mathrm{~K}$ at all altitudes above $30 \mathrm{~km}$ (less than $0.5 \mathrm{~K}$ between 20 and $30 \mathrm{~km}$ ).

As pointed out e.g. by Leblanc et al. (1998) or Sica et al. (2001), extinction by ozone between the altitudes $z$ and $z_{0}$ also needs to be accounted for, when the wavelengths of interest are absorbed by ozone, e.g. at $532 \mathrm{~nm}$. However, since ozone absorption at 353 or $355 \mathrm{~nm}$ is very small, it can be neglected here (at $308 \mathrm{~nm}$ it would be major). Resulting temperature errors are negligible, less than $0.03 \mathrm{~K}$ at altitudes above $25 \mathrm{~km}$. Below $25 \mathrm{~km}$, however, uncertainty in the assumed atmospheric transmission due to aerosol and Rayleigh scattering, as well as the additional scattering by stratospheric aerosol, can limit the accuracy of lidar temperature measurements severely. The DWD lidar, therefore does not report temperatures much below $30 \mathrm{~km}$. The NASA lidar uses Raman channels, which are much less affected by

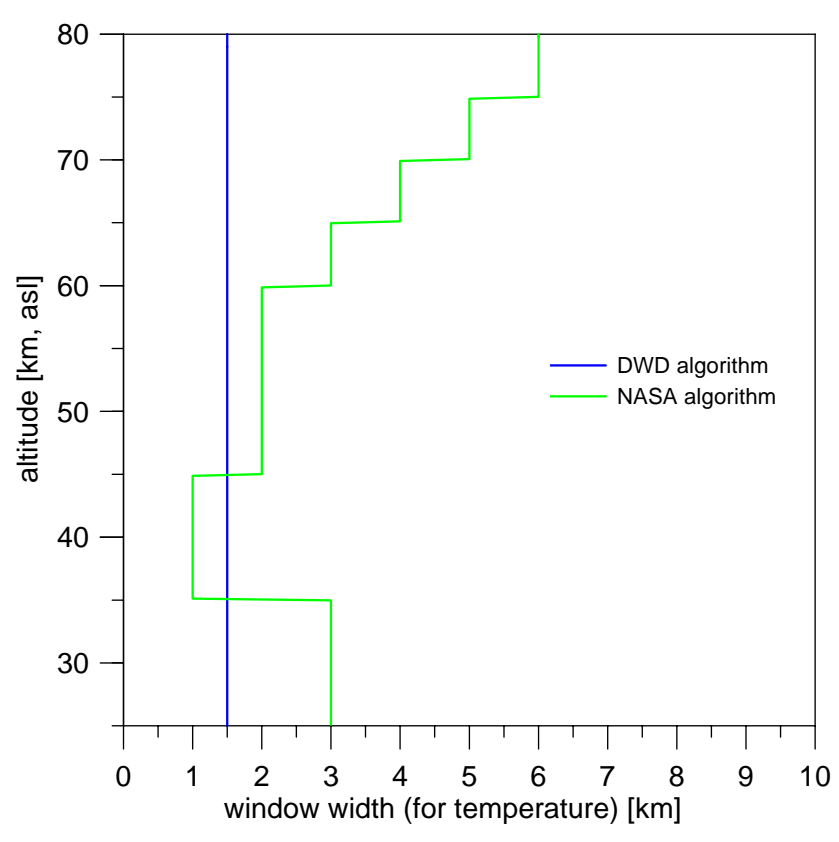

Fig. 5. Range resolution for the NASA and DWD temperature processing algorithms.

aerosol, and allow to measure temperature down to about $10 \mathrm{~km}$ (Gross et al., 1997).

As with ozone, the DWD and NASA temperature algorithms do some vertical smoothing on the lidar return signal $P_{\text {off }}(z)$ to reduce photon count noise. The DWD algorithm uses a fixed 5 point $(1.5 \mathrm{~km})$ boxcar average at all altitudes. The NASA algorithm uses a variable width boxcar, with widths less than $3 \mathrm{~km}$ below $65 \mathrm{~km}$, increasing to $6 \mathrm{~km}$ above $75 \mathrm{~km}$. Figure 5 shows the widths of the running averages for the DWD and NASA algorithms. This width is a measure for the range resolution $\Delta z$ of the retrieved temperature profiles. From Fig. 5 it is obvious, that temperature profiles retrieved by the DWD algorithm have the finer altitude resolution at most altitudes. However, combined with the DWD lidars much lower photon counts, this results in much noisier temperature data than from the NASA lidar.

\section{Campaign overview}

During October 2005, two stable tropospheric high pressure systems provided excellent weather conditions for the HOPE intercomparison. The first system moved north-easterly, from Northern France to Scandinavia, over the period from 14 to 20 October 2005. The second system was a long ridge moving from the Azores to the Baltic between 23 October and 1 November 2005. Both periods provided excellent clear nights for lidar measurements. Accordingly, the DWD and NASA-GSFC lidars were run simultaneously for 13 clear nights from 14 October to 31 October 2005. Both systems fired 50 laser pulses per second, synchronized to the 


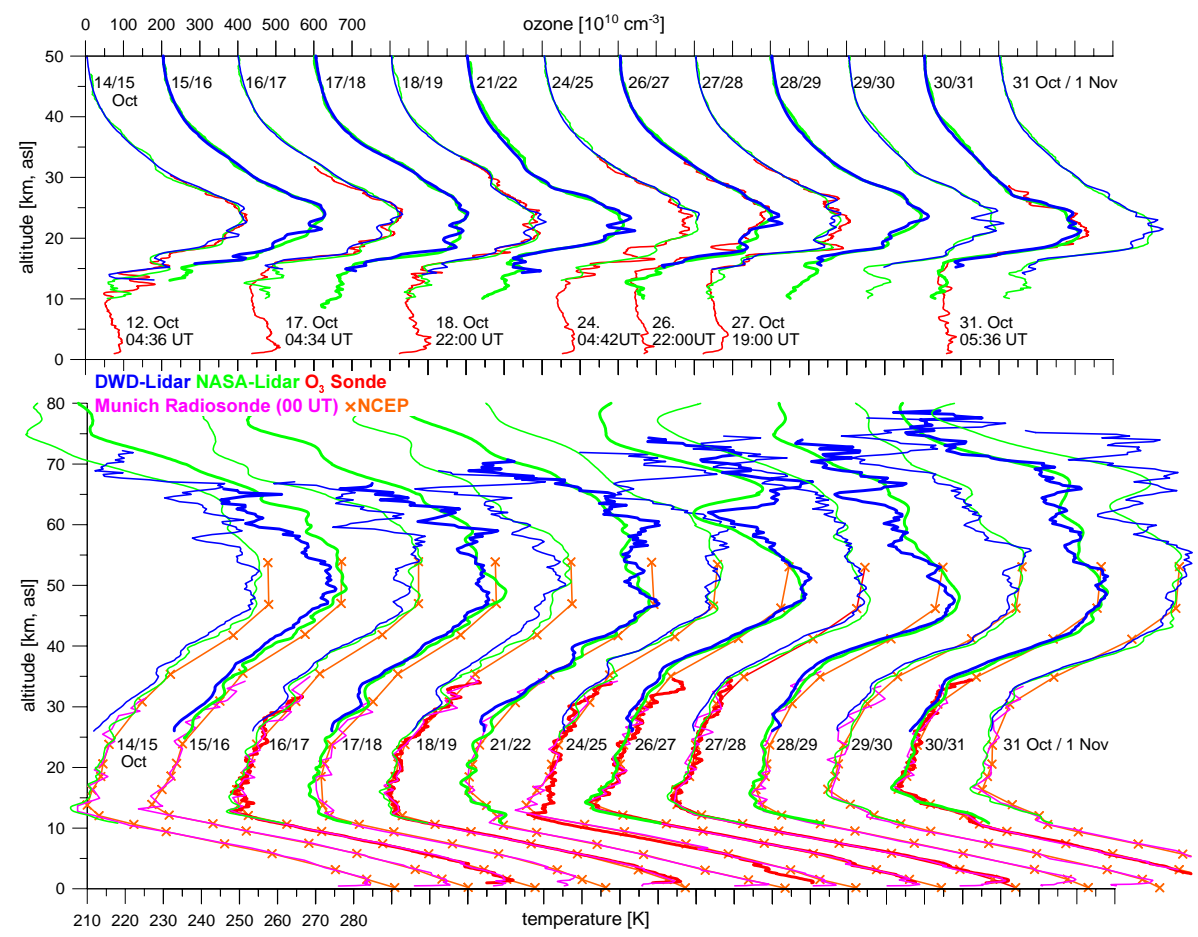

Fig. 6. Top: Ozone profiles measured between 12 October 2005 and 1 November 2005 at Hohenpeißenberg by DWD lidar (blue), NASA lidar (green), and by Hohenpeißenberg ozonesondes (red). The lidar profiles are nightly means. For the sondes, the launch time is given in UT (universal time=local time $-1 \mathrm{~h}$ ). Bottom: Same, but for temperature profiles measured by DWD Lidar (blue), NASA lidar (green), Hohenpeißenberg ozonesondes (red), and Munich radiosondes (magenta, 23:00 UT launch time). Also shown is the 00:00 UT temperature profile (orange) interpolated from the daily 12:00 UT analyses of the US National Centers for Environmental Prediction (NCEP).

chopper of the DWD system, but at different times. This synchronization allowed both systems to acquire data simultaneously, without laser pulses from one system interfering with the other. For additional ozone profiles, seven Brewer/Mast ozonesondes were launched at Hohenpeißenberg. Daily temperature profiles came from the Vaisala RS92 radiosondes at the nearby station Munich $(65 \mathrm{~km}$ north-east, near mid-night, 00:00 UT), and from interpolation of 12:00 UT meteorological analyses by the US National Centers for Environmental Prediction (NCEP).

Figure 6 gives an overview of all ozone and temperature profiles during HOPE. The top panel shows the ozone profiles from the two lidar systems, and the Hohenpeißenberg ozonesondes. The bottom panel shows the temperature profiles. The lidars usually operated from one hour after sunset to one hour before sunrise, providing a nightly mean profile centered around local midnight (23:00 UT). If clouds moved in during the night, the lidar measurement was terminated earlier. Ozone- and radiosondes provide a snapshot only, which starts at launch-time at the ground, and ends about 90 min later at 30 to $35 \mathrm{~km}$ altitude. Four of the Hohenpeißenberg ozonesondes were launched at their usual early morning launch-time, after the lidar measurement. The other three ozonesondes were launched at night, to obtain better overlap with the lidars.
As expected for October, ozone number densities reached their maximum around 22 to $25 \mathrm{~km}$ altitude above sea level, at 3 to $4 \times 10^{18}$ molecules per cubic meter. As usual, only small ozone variations were observed in the photochemically controlled altitudes above $25 \mathrm{~km}$. Larger spatial and temporal variations were seen in the transport-controlled region below. Most of the time, ozone structures are reported in good agreement by all instruments, e.g. on 16 to 17 October 2005 near $21 \mathrm{~km}$, or on October 27 to 28 October 2005 near $19 \mathrm{~km}$. Sometimes, e.g. on 24 to 25 October 2005 near $18 \mathrm{~km}$, the sonde reported a layer of low ozone not seen by the lidars. The two lidar systems show generally good agreement, with systematically higher ozone values reported by the NASA lidar around 35 to $40 \mathrm{~km}$. Random ozone differences, with a slight tendency to higher values from the NASA lidar, are seen at altitudes near 18 to $22 \mathrm{~km}$. There, the DWD lidar switches from the noisy near-range signal (acquired during the first and last hour of the night) to the far-range signal (acquired during the remainder of the night). The NASA lidar acquires near-range, far-range and Raman return signals simultaneously, throughout the night. By combining all these channels, ozone profiles from the NASA lidar reach further down, usually to $9 \mathrm{~km}$. The DWD lidar reports ozone only down to about $15 \mathrm{~km}$. In general, Fig. 6 shows good agreement between ozone from lidars and sondes. 
The temperature profiles are summarized in the lower panel of Fig. 6. The regular Munich mid-night radiosondes, and the occasional Hohenpeißenberg ozonesondes cover the temperature profile from the ground up to 30 or $35 \mathrm{~km}$. The DWD lidar gives temperature from $30 \mathrm{~km}$ up to $75 \mathrm{~km}$. At altitudes below $\approx 28 \mathrm{~km}$ the DWD lidar temperature measurement ends, because backscattering from the stratospheric aerosol layer begins to interfere. For the NASA lidar, the Raman channels are not affected much by aerosol, and allow temperature measurements down to $10 \mathrm{~km}$. Due to its much more powerful return signal and coarser altitude resolution, the NASA lidar can measure temperature up to $90 \mathrm{~km}$. The DWD lidar resolves finer temperature structures, but also shows higher noise. Both lidars show general agreement on the form of the temperature profiles and their major features. The large warming pulse near $65 \mathrm{~km}$ on 26 to 27 October 2005 , for example, is reported by both lidars, as are the temperature minima and maxima near 60 and $66 \mathrm{~km}$ on 31 October/1 November. The DWD lidar reports the 26 to 27 October 2005 temperature peak already in the previous night near $70 \mathrm{~km}$, whereas this earlier peak is not resolved well in the NASA temperature profile.

Both lidars tend to report slightly lower temperatures than the radiosondes in the 25 to $30 \mathrm{~km}$ region. Between 30 and $45 \mathrm{~km}$, and during the first part of HOPE, the NCEP layer mean temperatures are also often higher than the lidar temperatures. The DWD lidar usually reports slightly lower temperatures than the NASA lidar in the 28 to $50 \mathrm{~km}$ region. As expected, since they use the same radiosonde type, temperatures agree very well between Munich and Hohenpeißenberg sondes. With the exception of temperature inversions near the ground, sondes and NCEP analyses agree very well too. This is also expected, because the analyses are based on assimilated radiosonde data.

\section{Ozone and temperature differences}

\subsection{Individual nightly means}

A more detailed picture of the ozone differences is given in Fig. 7. It shows the relative ozone difference between DWD and NASA lidar for all 13 nights. Before calculating difference profiles, all profiles were converted to a common $1 \mathrm{~km}$ altitude grid, by averaging over the finer altitude bins available for the two lidars (and the sondes). Between 20 and $40 \mathrm{~km}$, ozone differences between both lidars show low standard deviations, less than $10 \%$. This is the altitude range where both systems give their most precise ozone measurements. From 23 to $33 \mathrm{~km}$, ozone differences are very close to zero. From 34 to $39 \mathrm{~km}$, all ozone differences are negative, indicating that the DWD lidar reports systematically lower ozone values than the NASA lidar. Near $20 \mathrm{~km}$, there is also a tendency for negative differences, i.e. lower values from the DWD lidar. Above $42 \mathrm{~km}$, the standard deviation

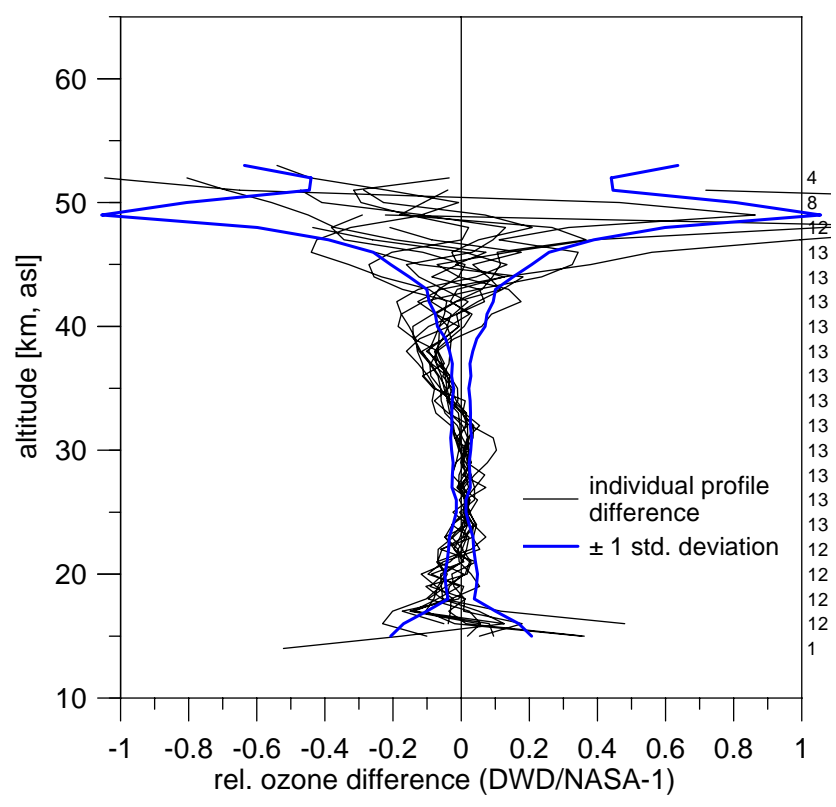

Fig. 7. Relative difference between nightly mean ozone number density from DWD and NASA lidar. The NASA profiles serve as the reference. The blue lines give plus and minus one standard deviation, offset from the zero line. Numbers on the right give the number of available ozone difference profiles.

of the ozone differences increases dramatically, from $7 \%$ at $40 \mathrm{~km}$ to more than $100 \%$ at $49 \mathrm{~km}$. Above $50 \mathrm{~km}$, the differences scatter widely, and the number of available comparisons drops from 12 at $49 \mathrm{~km}$ to 0 at $54 \mathrm{~km}$, as the DWD lidar reaches its upper range limit for ozone. On the whole, Fig. 6 indicates fairly consistent ozone differences, less than $10 \%$ between 20 and $35 \mathrm{~km}$, and reproducible to within 5\% from 18 to $39 \mathrm{~km}$.

The nightly mean temperature differences are given in Fig. 8. Between 30 and $60 \mathrm{~km}$, differences are usually negative, indicating that the NASA lidar gives around $2 \mathrm{~K}$ higher temperatures than the DWD lidar. From 30 to $50 \mathrm{~km}$, temperature differences are reproducible to within $2 \mathrm{~K}$. Above $55 \mathrm{~km}$, standard deviation increases. Near $70 \mathrm{~km}$, the DWD lidar reaches its upper range limit, and the number of available profiles drops rapidly.

\subsection{Precision estimates}

The standard deviation $\sigma$ of the ozone and temperature differences in Figs. 7 and 8 can be used to check the precision estimates $\Delta X$ provided by the data processing algorithms for the two lidars. Largely, the precision of ozone and temperature profiles measured by a lidar is controlled by the statistical noise of the return signal photon counts (Hauchecorne and Chanin, 1980; Megie et al., 1985). If the first lidar estimates precision $\Delta X_{1}$ for its nightly mean ozone or temperature profile $X_{1}$, and the second system estimates 


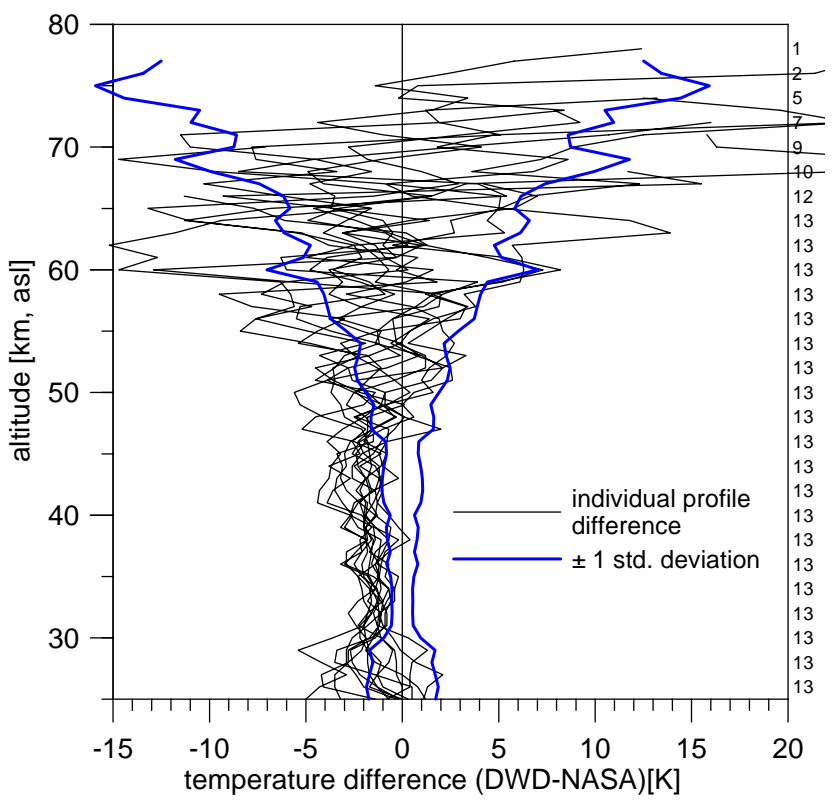

Fig. 8. Same as Fig. 7, but for the absolute temperature difference between DWD and NASA lidar. Note the different altitude range, from 25 to $80 \mathrm{~km}$, instead of from 15 to $65 \mathrm{~km}$ for the relative ozone differences in Fig. 7. Numbers on the right give the number of available temperature difference profiles.

precision $\Delta X_{2}$, the precision $\Delta_{\text {est }}(d X)$ for the difference profile $d X=X_{1}-X_{2}$ should be $\Delta_{\text {est }}(d X)=\left(\Delta X_{1}^{2}+\Delta X_{2}^{2}\right)^{\frac{1}{2}}$, since photon count noise for the two systems should be uncorrelated.

If $\Delta_{\text {est }}(d X)$ is correct, it should be approximately the same as the standard deviation $\sigma_{\text {meas }}(d X)$, e.g. of the 13 nightly mean difference profiles during HOPE (blue line in Figs. 7 and 8). If the observed standard deviation $\sigma_{\text {meas }}(d X)$ differs substantially from the estimated precision $\Delta_{\mathrm{est}}(d X)$, this indicates that either $\Delta X_{1}$, or $\Delta X_{2}$ (or both) are not correct. Note, however, that this check alone is not conclusive. Only gross errors in $\Delta X_{i}$ can be discovered. For example, $\Delta X_{1}$ could be too low, $\Delta X_{2}$ could be too high, but $\Delta_{\text {est }}(d X)$ could still come out correct.

Figures 9 and 10 show the precision estimates for ozone and temperature for the two lidars $\left(\Delta X_{i}\right.$, blue and green lines), and the precision estimate for the difference between the two lidars $\left(\Delta_{\text {est }}(d X)\right.$, black lines). The red lines give the observed standard deviation $\sigma_{\text {meas }}(d X)$ of difference profiles during HOPE. For ozone, observed standard deviation and estimated precision behave similarly with altitude, with the best precision (lowest values) in the 20 to $40 \mathrm{~km}$ region. From 17 to $42 \mathrm{~km}$, estimated precision and observed standard deviation are better (lower) than $10 \%$. From 18 to $39 \mathrm{~km}$, they are better than $5 \%$. Below $28 \mathrm{~km}$, the estimated ozone precision for the DWD lidar (blue line) is worse (larger values) than for the NASA lidar (green line). This is due to the weaker return signals (compare Fig. 2), and the shorter

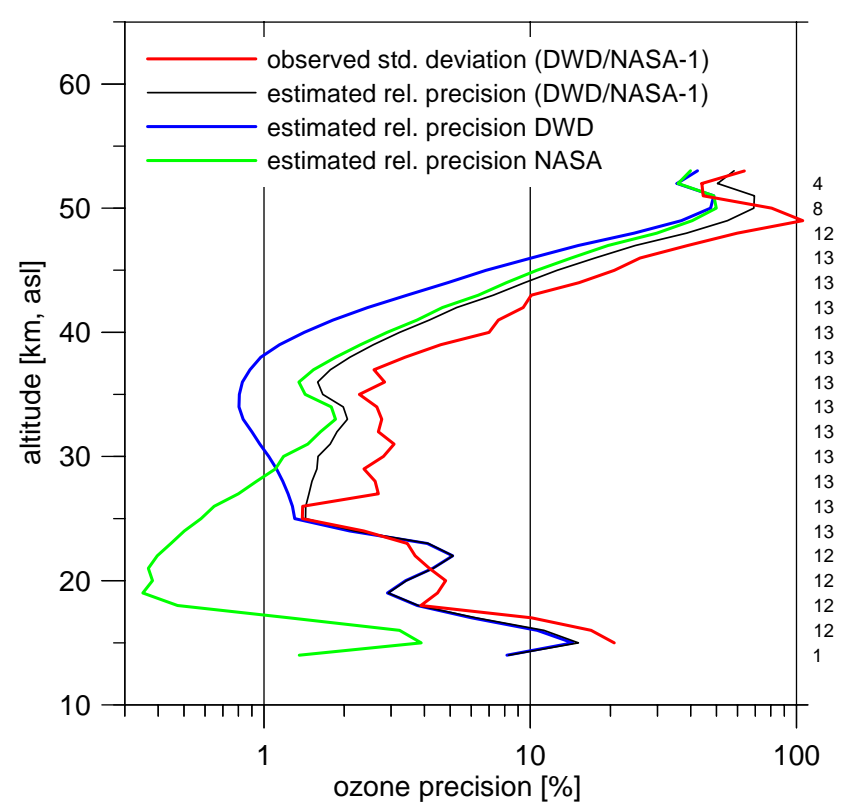

Fig. 9. Relative precision estimates $\Delta X_{i}$ for ozone profiles from DWD (blue line) and NASA lidar (green line) during HOPE. Black line: Precision estimate $\Delta_{\text {est }}(d X)$ for the ozone relative difference $d X$. Red line: Observed standard deviation $\sigma_{\text {meas }}(d X)$ of relative ozone differences during HOPE (same as blue curve in Fig. 7). Numbers on the right give the number of ozone difference profiles during HOPE.

measurement time for the DWD near-range signals (below $22 \mathrm{~km}$ ). Between 30 and $50 \mathrm{~km}$, the estimated precision for the DWD lidar is slightly better than for the NASA lidar. At these altitudes, the much smaller photon counts of the DWD lidar are compensated by the much coarser altitude resolution of the DWD algorithm (compare Fig. 4).

Below $25 \mathrm{~km}$, the agreement between observed standard deviation and estimated precision of the ozone differences is good. In this altitude region, the estimated precision of the difference (black line) is almost entirely controlled by the poor precision (large values) of the DWD lidar (blue line). The agreement between observed standard deviation (red line) and estimated precision of the ozone differences (black line) below $25 \mathrm{~km}$ indicates that the ozone precision estimate from the DWD lidar is correct there.

From 27 to $48 \mathrm{~km}$ altitude, however, the estimated precision (black line) is better (smaller values) than the observed standard deviation (red line), by a factor of about 0.7. This indicates that the precision is under-estimated for at least one of the lidars. Comparison of ozone standard deviation and estimated precision for the DWD lidar over many years (not shown) indicates that the precision estimate for this lidar is correct above $45 \mathrm{~km}$, where the observed standard deviation is dominated by statistical noise. For the NASA lidar during HOPE, however, the standard deviation between 45 and $50 \mathrm{~km}$ (not shown) is larger than for the DWD lidar, by a 


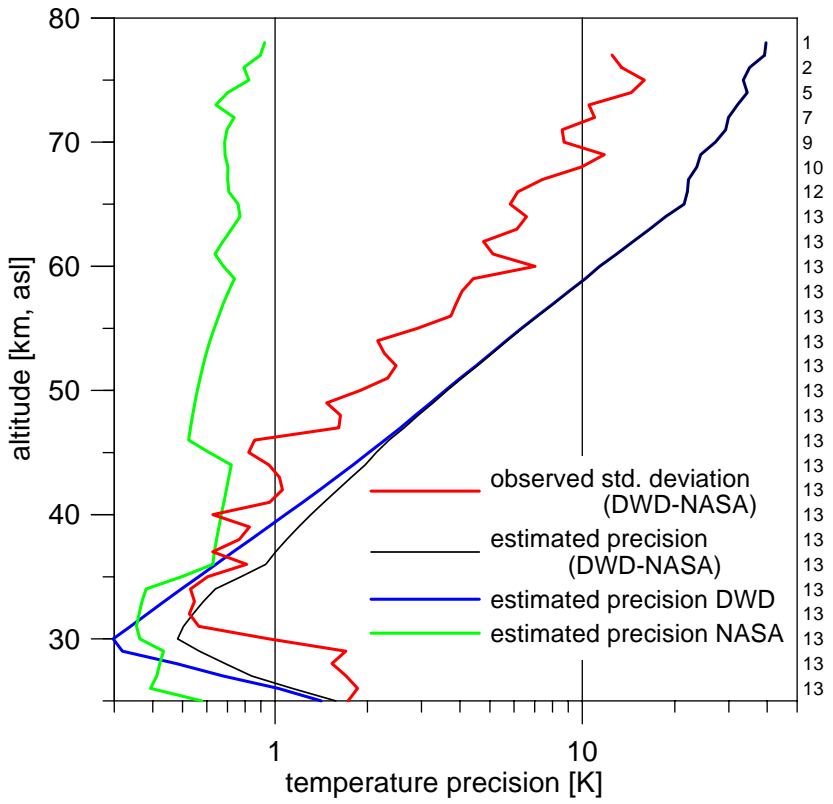

Fig. 10. Same as Fig. 9, but for estimated temperature precision $\Delta X_{i}$ for DWD (blue line) and NASA (green line) lidar, for the estimated precision $\Delta_{\text {est }}(d X)$ of temperature differences between the DWD and NASA lidars (black line), and for the observed standard deviation $\sigma_{\text {meas }}(d X)$ of temperature differences (red line=same as blue curve in Fig. 8). Numbers on the right give the number of available temperature difference profiles. Note the different altitude range, from 25 to $80 \mathrm{~km}$, instead of from 15 to $65 \mathrm{~km}$ for ozone in Fig. 9.

factor of about 1.7, although the estimated precisions are comparable. Multiplying the NASA ozone precision estimate ( $\Delta X$, green line) by a factor of 1.7 would also increase the estimate for the precision of DWD-NASA ozone differences $\left(\Delta_{\text {est }}(d X)\right.$, black line) between 25 and $50 \mathrm{~km}$. This would bring it into good agreement with the observed standard deviation $\left(\sigma_{\text {meas }}(d X)\right.$, red line) at all altitudes. From Fig. 9, and some additional information, it appears that the ozone precision values given by the NASA algorithm are currently too small by a factor of about 1.7 . We do not think that this has major implications for previous intercomparisons of the NASA lidar. Most intercomparisons have looked at bias and standard deviations, and less attention has been given to the precision estimates (see summary by Keckhut et al., 2004).

For temperature in Fig. 10, the observed standard deviation of DWD-NASA temperature differences $\left(\sigma_{\text {meas }}(d X)\right.$, red curve), as well as the precision estimate $\left(\Delta_{\text {est }}(d X)\right.$, black curve) increase with altitude, from $0.4 \mathrm{~K}$ around $30 \mathrm{~km}$ to more than $10 \mathrm{~K}$ above $70 \mathrm{~km}$. Different from ozone, the estimated precision for temperature differences (black curve) is much larger than the observed standard deviation (red curve). Figure 10 shows that the precision is over-estimated (values too large) by a factor of about 2. Since the black curve is almost entirely controlled by the estimated temperature precision from the DWD lidar ( $\Delta X$, blue line), the disagreement between the black and red curves points to an error in the DWD temperature precision estimate. In fact, the current DWD processing does not account for the noise reduction obtained by averaging over 5 range bins (see discussion of Fig. 5). This should reduce statistical noise by a factor of $\sqrt{5} \approx 2.2$, roughly the same factor that would bring the black and red curves in Fig. 10 into agreement. Temperature precision for the NASA lidar ( $\Delta X$, green curve) is estimated to be between 0.4 and $1 \mathrm{~K}$. This is much better than for the DWD lidar, and is due to the much higher return signals and the coarser altitude resolution for the NASA lidar. Since the estimated temperature precision for the NASA lidar is so much better (smaller), Fig. 10 does not provide much information about correctness of the NASA precision estimate for temperature.

\subsection{Average ozone differences}

We now return to the topic of systematic differences between the different instruments. Figure 11 shows the average relative ozone difference between DWD and NASA lidar during HOPE (blue line). The blue line in Fig. 11 is the average of the 13 individual difference profiles given in Fig. 7. Systematic ozone differences seen previously for the DWD lidar against the SAGE II and GOMOS satellite instruments (Steinbrecht et al., 2006; Meijer et al., 2004) are plotted as well (black and green lines). All profiles look very similar. Error bars overlap at nearly all altitudes. In all comparisons, the DWD lidar profiles have a clear negative bias between 33 and $43 \mathrm{~km}$, by up to $15 \%$ near $39 \mathrm{~km}$. Between 23 and $33 \mathrm{~km}$, the DWD profiles agree within $2 \%$ with NASA lidar and SAGE II. GOMOS seems to have a high bias, but error bars are larger as well.

Near $20 \mathrm{~km}$ and below, the DWD lidar gives up to $7 \%$ lower ozone values than the NASA lidar (blue curve). A similar difference is seen against SAGE II and GOMOS (black and green curves). Lower ozone values are also reported by the ozonesondes below $20 \mathrm{~km}$ (red line), but the sondes are consistent with the DWD lidar there. The sondes also show a low bias above $30 \mathrm{~km}$. The latter bias is well known and is attributed to an insufficient correction of decreasing pump efficiency at low ambient pressure (Steinbrecht et al., 1998, WMO correction is still used).

Figure 12 addresses the question, why the DWD lidar consistently underestimates ozone in the 33 to $43 \mathrm{~km}$ region. The figure compares the systematic difference observed during HOPE (blue line), with differences generated by the DWD ozone processing algorithm. The DWD algorithm has been tested previously with synthetic simulated lidar return signals in the NDSC algorithm intercomparison (Godin et al., 1999, red line). There, the DWD ozone algorithm showed a bias very similar to the ozone difference found in HOPE. A slight shift towards lower altitudes comes from the different ozone 


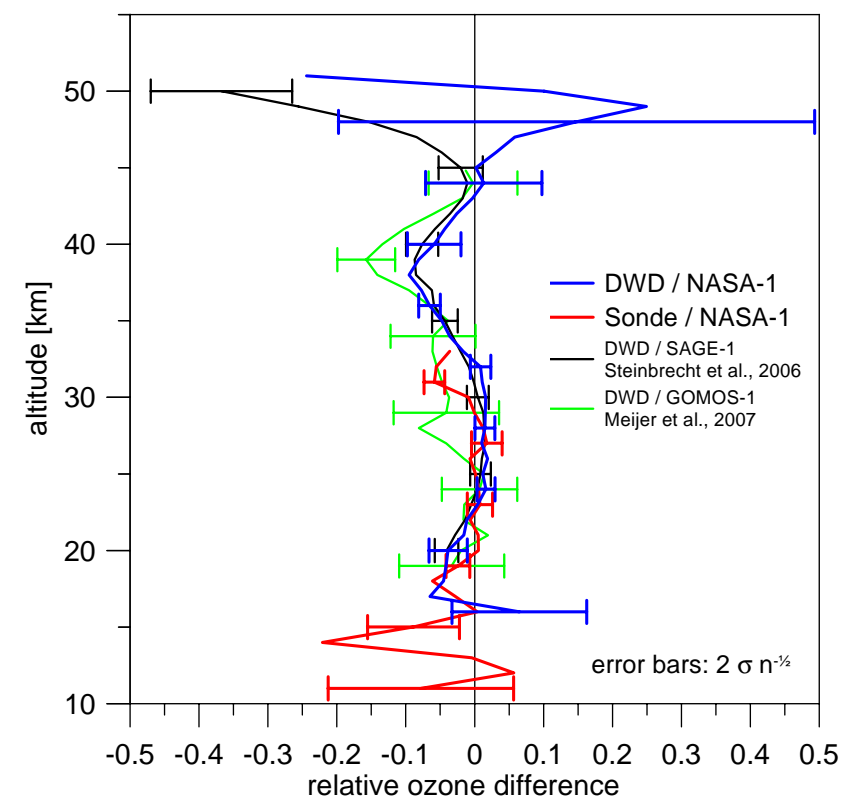

Fig. 11. Average relative ozone difference profiles. Blue: Between DWD and NASA lidars during HOPE. Red: Between ozonesondes and NASA lidar during HOPE. Black: Average difference between DWD lidar and SAGE II (version 6.2) over the period 1987 to 2005 (Steinbrecht et al., 2006). Green: Average difference between DWD lidar and GOMOS (version 6.0f, updated from Meijer et al., 2004). Error bars: Two standard errors of the mean.

profile used in this NDSC algorithm intercomparison. For HOPE, return signals from the NASA lidar were also processed with the DWD algorithm. The black line gives the resulting DWD-NASA ozone difference. As in the Godin et al. (1999) NDSC algorithm intercomparison, this difference comes from the processing algorithm, more specifically from the differential filters used in the DWD and NASA algorithm (compare Fig. 3). For HOPE, the difference caused by the DWD algorithm is virtually the same as the observed ozone difference (blue line). From the good agreement between observed ozone difference during HOPE and the bias found for the DWD algorithm in Fig. 12, it becomes clear that the bias of the DWD lidar ozone profiles against several other instruments in the 33 to $43 \mathrm{~km}$ region is caused by the DWD processing algorithm, not by the lidar hardware. In Sect. 5, we will show that a corrected version of the DWD ozone processing gives much better agreement with the NASA lidar or SAGE.

\subsection{Average temperature differences}

The average temperature difference profiles are given in Fig. 13. Temperatures from DWD lidar, NCEP operational analyses, and from Munich radiosondes are referenced to the NASA lidar temperature. From $25 \mathrm{~km}$ to $65 \mathrm{~km}$, the DWD lidar measures on average 1 to $2 \mathrm{~K}$ lower temperature than the NASA lidar. This difference is statistically significant

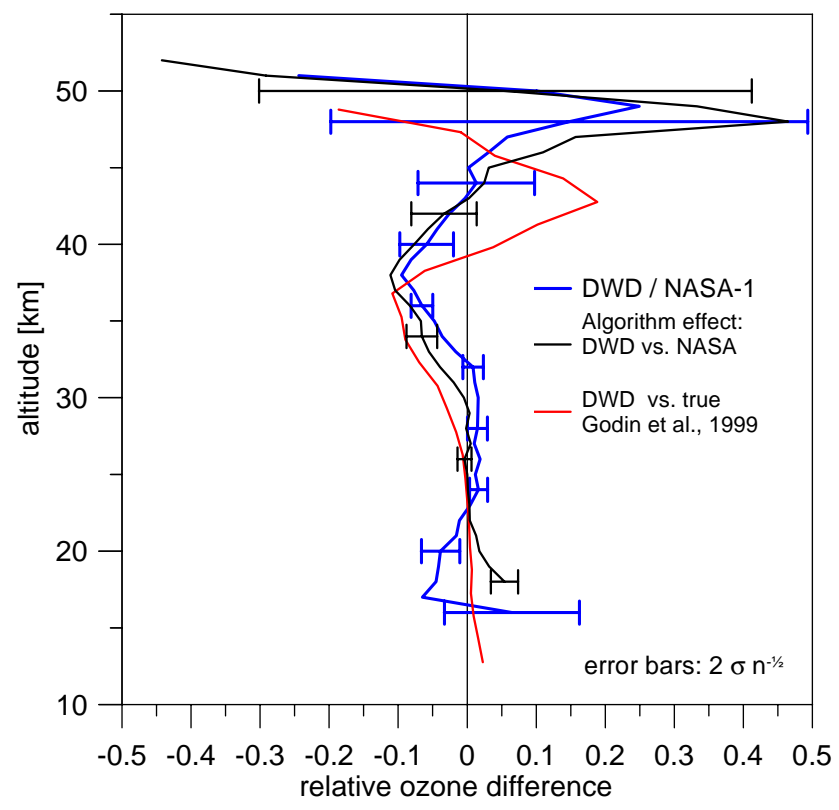

Fig. 12. Blue line: Observed relative ozone difference between DWD and NASA lidar during HOPE, same as in Fig. 11. Black line: Relative ozone difference between NASA lidar return signals processed by DWD algorithm and processed by NASA algorithm. Red line: Bias of the DWD algorithm in the NDSC algorithm intercomparison (Godin et al., 1999). Error bars are two standard errors of the mean.

from 25 to $50 \mathrm{~km}$. Above $65 \mathrm{~km}$, the DWD lidar reports up $15 \mathrm{~K}$ higher temperature than the NASA lidar, but this is not statistically significant. The NASA lidar itself reports about $1 \mathrm{~K}$ lower temperatures than NCEP at most altitudes. This is statistically significant between 16 and $36 \mathrm{~km}$. NASA lidar temperatures are also between 0.2 and $1.2 \mathrm{~K}$ lower than temperature measured by the Munich radiosondes between 15 and $33 \mathrm{~km}$. This is often not statistically significant, but in agreement with the NCEP temperatures. All differences seem to be fairly constant over a wide altitude range. From Fig. 13 it appears that

1. NCEP analyses provide very similar temperatures to the radiosondes, which are of course an important input to the analyses.

2. The NASA lidar reports about $1 \mathrm{~K}$ lower temperature than analyses or radiosondes.

3. The DWD lidar reports 1 to $2 \mathrm{~K}$ lower temperature than the NASA lidar, and 2 to $4 \mathrm{~K}$ lower temperature than NCEP analyses or radiosondes.

To put the HOPE temperature differences into a wider context, Fig. 14 compares them with long-term average temperature differences between NCEP and DWD lidar, and between Hohenpeißenberg soundings and DWD lidar. Note 


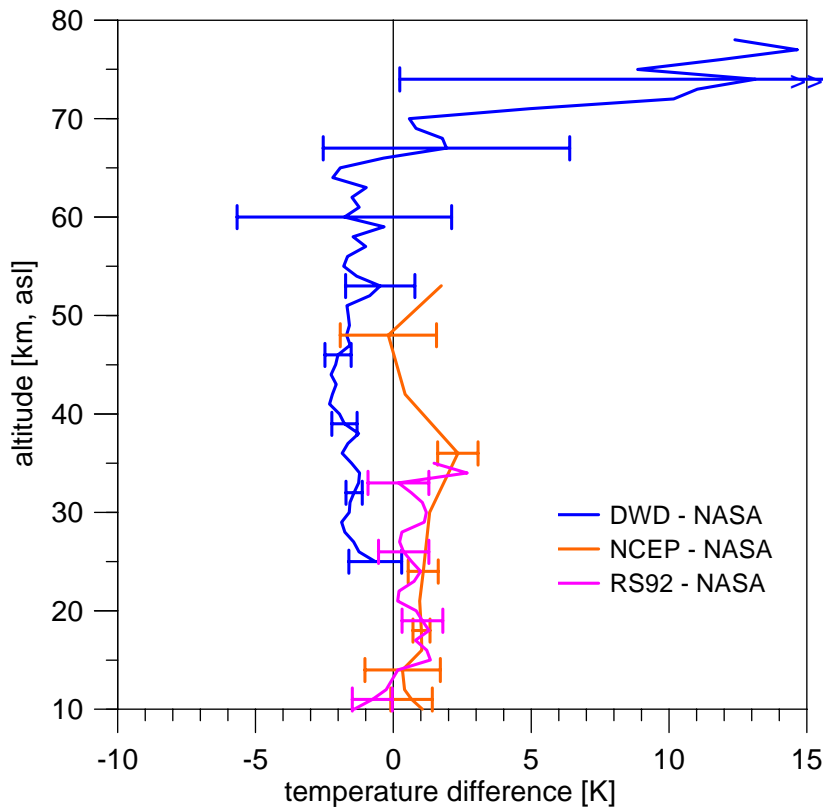

Fig. 13. Average temperature differences during HOPE. Blue: Between DWD and NASA lidar. Orange: Between NCEP operational analyses and NASA lidar. Magenta: Between Munich Vaisala RS92 radiosondes and NASA lidar. Error bars: Two standard errors of the mean.

that Fig. 14 uses the DWD lidar as the reference. The temperature differences during HOPE (orange, magenta and blue line) are fully consistent with the differences found previously, when comparing DWD lidar temperatures with NCEP over the period 2001 to 2007 , or with radiosondes over the period 1997 to 2007 (green and red lines). At all altitudes between 25 and $65 \mathrm{~km}$, the DWD lidar consistently reports between 1 and $4 \mathrm{~K}$ lower temperature. Systematic differences between RS80 and RS92 radiosondes (Steinbrecht et al., 2008) are minor in this context. Section 5 explains later, where much of this large temperature difference comes from.

\subsection{Correlation and scatter plots}

It is of course desirable that all instruments (and the NCEP analyses) should provide the same mean profiles of ozone and temperature. In addition, variations should also be tracked in the same way by all instruments. A climatology, for example, might give the correct mean profile, but it would probably not provide correct variations. To address this important aspect, Fig. 15 plots ozone variations measured by DWD lidar and ozonesondes against ozone from the NASA lidar, at different altitude levels. Ideally, all data points in each panel would lie on the 1 to 1 line, from bottom left to top right.

As expected, the lowest scatter and the tightest correlations are seen between 25 and $40 \mathrm{~km}$ altitude, the altitude range of best precision for the lidars. Both lidars report a similar range of ozone values, and highly correlated variations (correlation

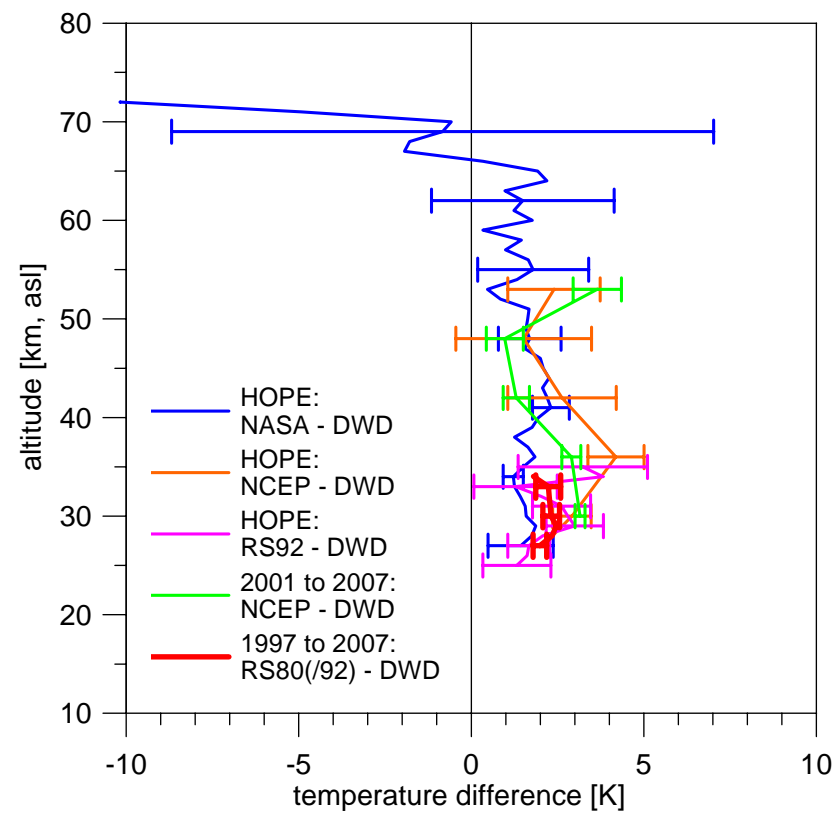

Fig. 14. Similar to Fig. 13 but for average temperature differences to the DWD lidar. Blue: NASA minus DWD lidar during HOPE. Orange: NCEP minus DWD lidar during HOPE. Magenta: $\mathrm{Mu}-$ nich radiosondes (Vaisala RS92) minus DWD lidar during HOPE. Green: NCEP minus DWD lidar over the period July 2001 to October 2007 (about 600 cases). Red: Hohenpeißenberg sondes minus DWD lidar, over the period October 1997 to October 2007 (about 300 cases, sondes launched within $10 \mathrm{~h}$ of the lidar measurement). Error bars: Two standard errors of the mean.

$R>0.9$ ). However, because of the systematic underestimation by the DWD algorithm (see Figs. 11 and 12), most blue data points at 35 and $40 \mathrm{~km}$ altitude fall below the 1 to 1 line. As noise increases with altitude above $40 \mathrm{~km}$, data points scatter more widely and lie more or less randomly around the 1 to 1 line. At 15 and $20 \mathrm{~km}$, the larger spatial and temporal variability of ozone (compare Fig. 6), and the poorer precision of the DWD lidar (compare Fig. 9), also result in increased scatter. Ozonesonde precision is around 5\% (e.g., Smit and Kley, 1998), and the scatter of the ozonesonde data in Fig. 15 is comparable to the lidar results. Even the two sondes with poor temporal matches (circled triangles in Fig. 15; 12 October 2005, more than $60 \mathrm{~h}$ before a lidar measurement, 24 October $2005,12 \mathrm{~h}$ before a lidar measurement), give data in the range of the other sondes, launched within 2 to $6 \mathrm{~h}$ of the lidar measurement.

Figure 16 gives the vertical profile of the correlation coefficient between ozone variations from the different instruments during HOPE. Ozone measured by the DWD lidar correlates slightly better with NASA ozone than with ozone from the sondes. The confidence interval is also narrower. For the DWD lidar, correlation with NASA ozone is significantly larger than zero at most altitudes between 15 and $42 \mathrm{~km}$. Between 25 and $37 \mathrm{~km}$, ozone correlation between the two 

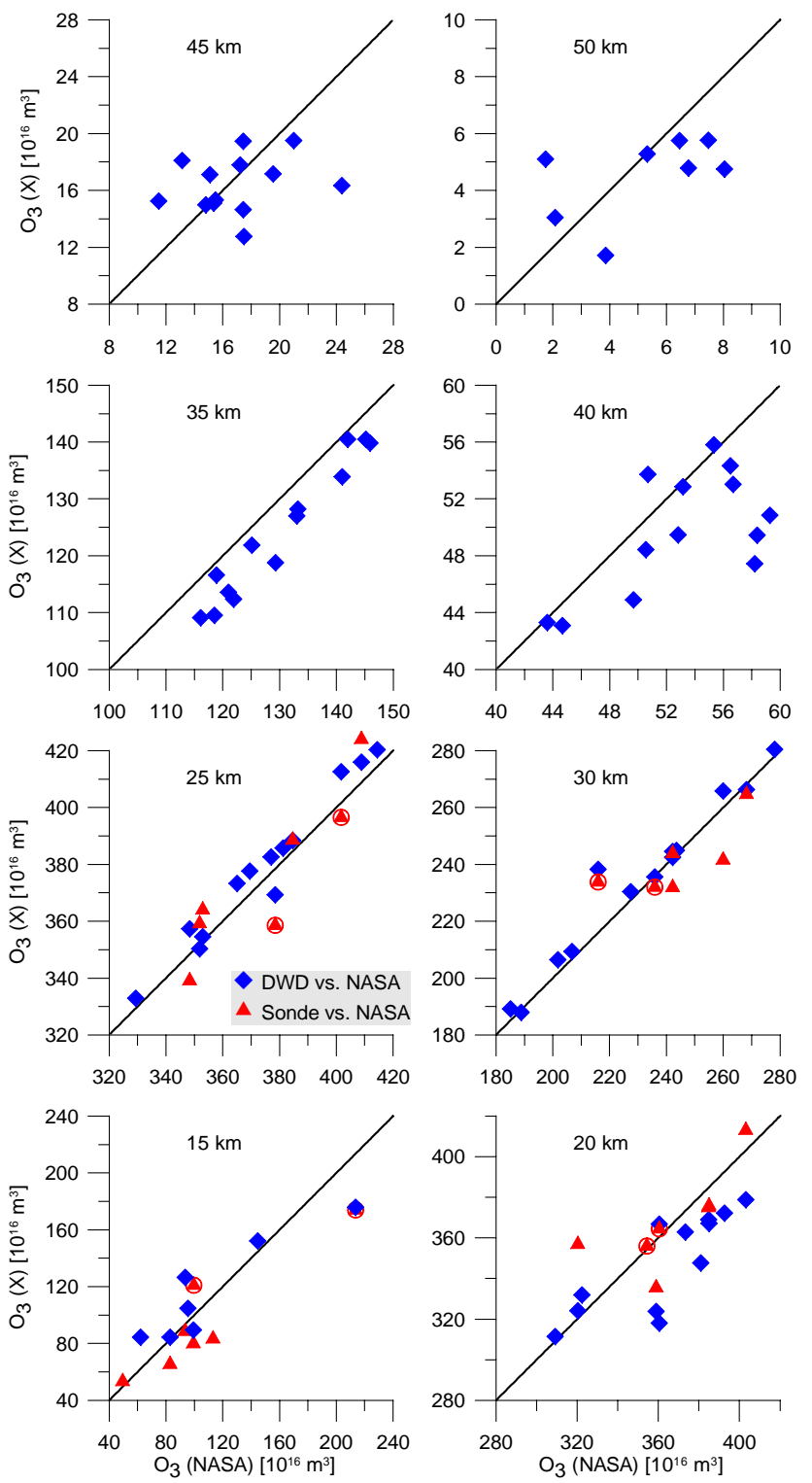

Fig. 15. Scatter plots of ozone number density during HOPE at selected altitude levels. Ozone measured by DWD lidar (blue diamonds), and ozonesondes (red triangles) is plotted against ozone from the NASA lidar. Ozonesondes were launched within $6 \mathrm{~h}$ of the lidar measurement, except for the two sonde points indicated by a red circle around the red triangle (12 and 24 October 2005 launches). Each data point represents an ozone value from a sonde and/ or nightly mean ozone from a lidar.

lidars is better than 0.9. From 40 to $50 \mathrm{~km}$ measurement noise increases substantially. The correlation drops from 0.8 to near zero. Below $25 \mathrm{~km}$, correlations range between 0.5 and 0.9, and are similar for DWD lidar and ozonesondes. The poor correlation around $22 \mathrm{~km}$, near the ozone maximum, is attributed to small-scale structures that vary with time and location and are sampled differently by the sondes and the two lidars (compare Fig. 6).

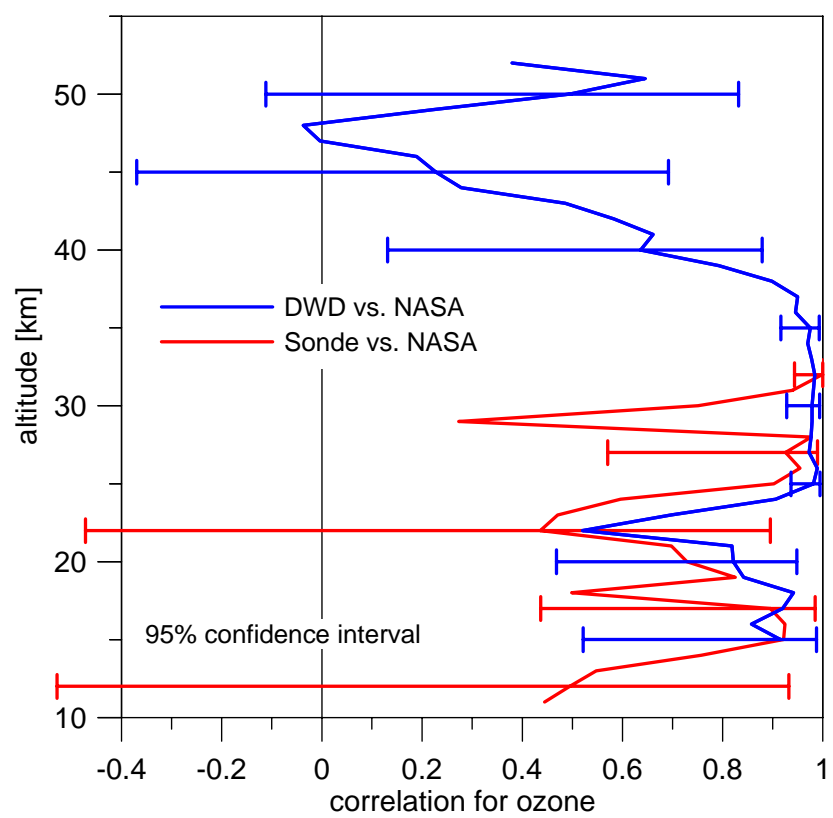

Fig. 16. Linear correlation coefficient between ozone measured by DWD lidar and ozone from the NASA lidar(blue line), or between ozonesondes (red line) and NASA lidar. Error bars give the $95 \%$ confidence interval.

Figures 17 and 18 plot the temperatures recorded by the other instruments during HOPE against temperature from the NASA lidar. From 30 to $42 \mathrm{~km}$, all data sources show very similar variations. Data points lie close to the ideal 1 to 1 line, with an apparent warm bias for NCEP analyses and radiosondes, and an apparent cold bias for the DWD lidar (compare Fig. 13). At higher altitudes (48 to $70 \mathrm{~km}$ ), data points scatter more widely, as the measurements become increasingly noisy. The two top-most layers of the NCEP analyses (48 and $53 \mathrm{~km}$, or 1 and $0.4 \mathrm{hPa}$ ) show little correlation with temperature from the NASA lidar (or the DWD lidar). Temperature correlation between the two lidars is generally better, and appears to be useful up to $70 \mathrm{~km}$.

For the lower levels (Fig. 18), data points from radiosondes and NCEP are very similar, and are generally close to the 1 to 1 line. Radiosonde and NCEP temperatures correlate well with the NASA lidar results. Vertical profiles of the correlations are given in Fig. 19. With the exception of the NCEP data around $14 \mathrm{~km}$, correlations with the NASA lidar data are larger than 0.8 for all data sets at all levels up to $37 \mathrm{~km}$. Closer inspection in Fig. 6 indicates that the large scale NCEP data do not resolve local details of the tropopause near $14 \mathrm{~km}$. Usually, however, correlation between lidar and NCEP temperatures is slightly higher than between lidar and the sondes. Figure 6 indicates that the sondes report local short-term structures not present in the nightly mean lidar profiles and smooth NCEP profiles. Above $50 \mathrm{~km}$, correlation between the two lidars decreases, 

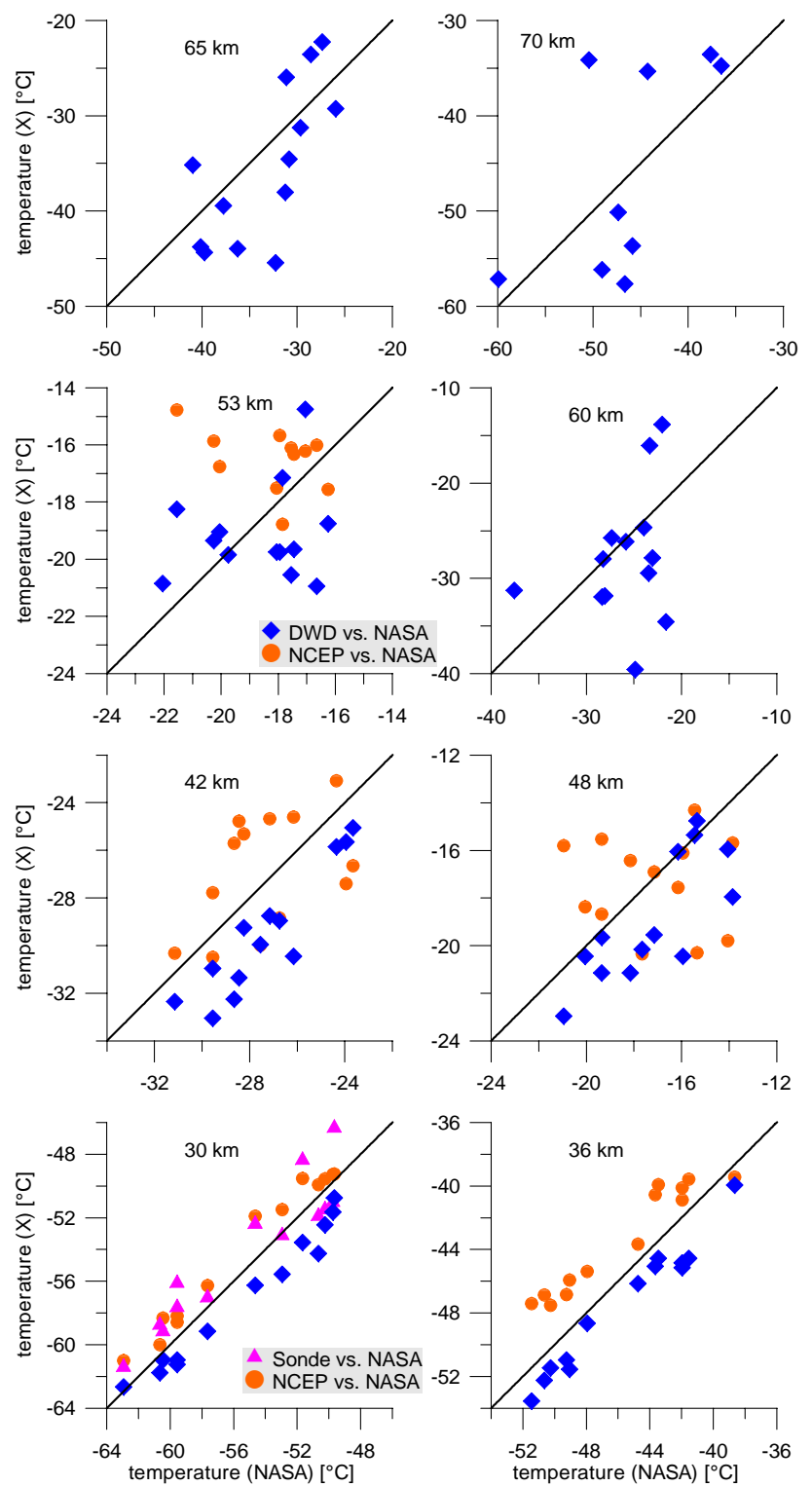

Fig. 17. Scatter plots for temperature during HOPE at selected altitudes. Temperatures from DWD lidar (blue diamonds), Munich radiosondes (magenta triangles), and NCEP (orange circles) are plotted against temperature from the NASA lidar.

because noise increases and the precision of the lidar temperature measurements drops, especially for the DWD lidar (see Fig. 9). Nevertheless, significant correlation appears up to $70 \mathrm{~km}$.

\section{Improved processing for the DWD lidar data}

When trying to explain the consistent low bias of the DWD lidar temperature data, e.g. in Fig. 13, a major advantage of the HOPE intercomparison was to have the directly comparable return signals $P(z)$ from the NASA lidar. In the end,
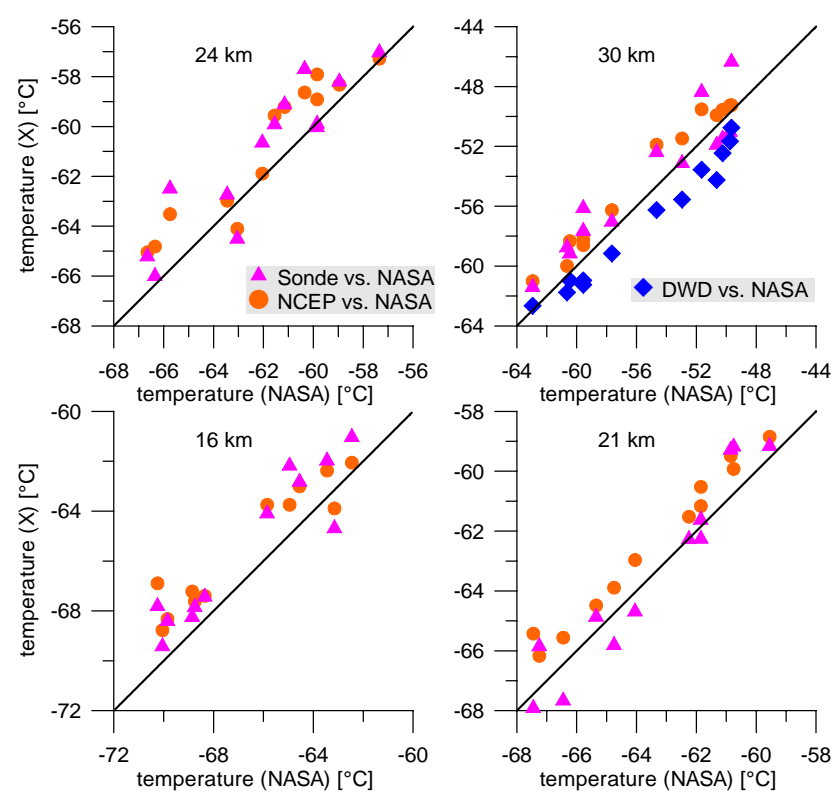

Fig. 18. Same as Fig. 17, but for altitudes between 16 and $30 \mathrm{~km}$. The DWD lidar does not report temperature below about $27 \mathrm{~km}$.

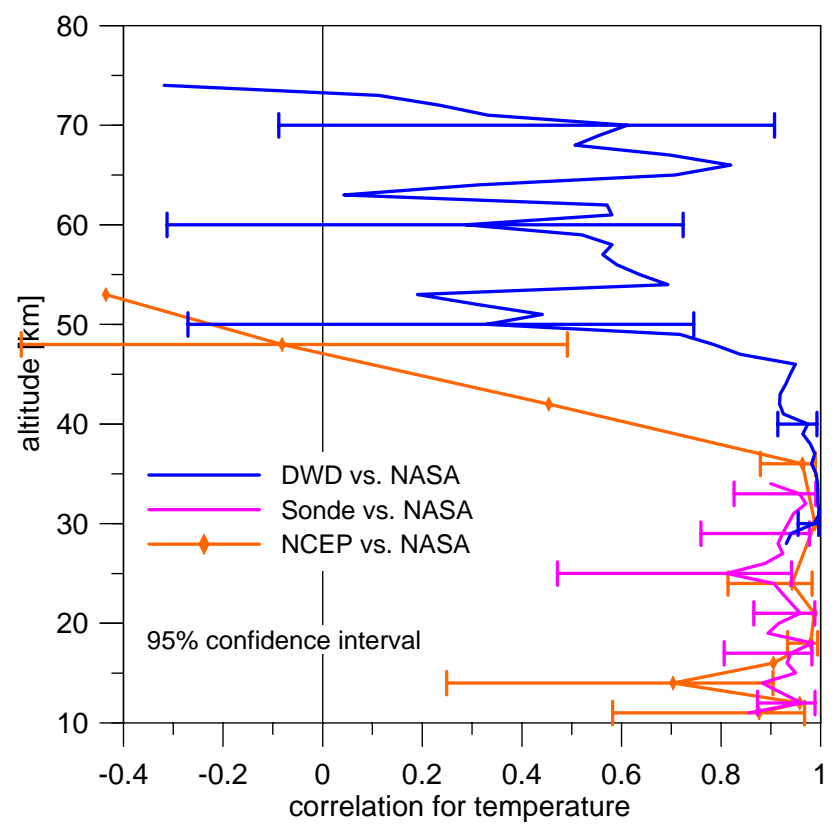

Fig. 19. Correlation coefficient between temperature from the NASA lidar and temperature from DWD lidar (blue line), Munich radiosondes (magenta line), and NCEP (orange line). Error bars give the $95 \%$ confidence interval.

analysis of the return signals from both lidars indicated a systematic error in the assigned altitude $z$ for the DWD lidar return signals. The ratio $P_{\mathrm{DWD}}(z) / P_{\mathrm{NASA}}(z)$, which should be constant with altitude, and the reported altitude of cirrus clouds showed that the assigned altitudes of the DWD lidar are too high by about $300 \mathrm{~m}$ during HOPE. Detailed tests 
with the DWD lidar confirmed this. The "laser-synch" trigger pulse, which starts the range measurement of the DWD lidar, comes $1.9 \pm 0.3 \mu \mathrm{s}$, or $290 \pm 45 \mathrm{~m}$, earlier than the actual optical pulse. Therefore, all altitudes reported by the DWD lidar are too high by about $290 \mathrm{~m}$, and need to be shifted downwards. This has consequences particularly for the temperature profiles, but also for the ozone profiles. Very likely, this shift has been present throughout the entire DWD lidar record since 1987.

A second major error is the consistent low bias of the DWD lidar ozone profiles in the 33 to $43 \mathrm{~km}$ region. This bias is obvious e.g. in Figs. 11 and 12. It has been observed in HOPE and in previous intercomparisons. As mentioned, the bias results from the smoothing properties of the wide differential filter used in the DWD ozone algorithm. It is largest in those regions, where the filter is very wide, and the curvature of the ozone profile is high (compare also Leblanc et al., 1998). In order to correct this bias, we have rescaled the derivative filters of the DWD ozone algorithm (compare Fig. 3), so that the correct ozone profile is returned, when the derivative filter is applied to vertically integrated climatological ozone profiles from SAGE, GOMOS, or HALOE. This improved DWD ozone algorithm uses the same shape as the old derivative filters, but the filters are rescaled. In this fashion nearly all filter properties are retained, but the filter bias is removed. The red line in Fig. 20 shows the effective ozone change due to the rescaled differential filter. Later, in Fig. 22, we will show convincing results for the new DWD ozone algorithm.

The third effect to be addressed is a better estimation of background levels. For most lidar systems, a slowly decaying background is superimposed onto the lidar return signals and the constant skylight background (Iikura et al., 1987; Williamson and Young, 2000). This "signal induced noise" decays slowly, with time constants between a few microseconds and milliseconds, corresponding to ranges between a few hundred meters and hundreds of kilometers. As mentioned in Sect. 2, signal induced noise is minimized by the mechanical chopper used in the DWD and NASA lidars. Still, it is not completely negligible (compare Table 1). Previous studies have shown that errors in background estimation can affect ozone and temperature profiles significantly at their far range limits (McDermid et al., 1990; McGee et al., 1995a; Leblanc et al., 1998). Typically, with uncorrected signal induced noise, ozone is underestimated. Temperature is overestimated. For single profiles from the DWD lidar, the uncertainty from background estimation is usually well within the statistical noise. However, when averaging over many profiles, it can become important. The NASA processing estimates signal induced noise using a linear, quadratic or exponential fit. Remaining ozone errors are negligible below $40 \mathrm{~km}$, and are estimated to be less than $5 \%$ at $45 \mathrm{~km}$, and less than $15 \%$ near $50 \mathrm{~km}$ (McGee et al., 1995a). At $355 \mathrm{~nm}$, signal induced noise is negligible, and temperature from the NASA lidar is not affected by it.
In the old DWD processing, signal induced noise has largely been ignored. Part of that is for historical reasons. In the first 8 years of the time-series, the old data acquisition system recorded signals only up to $70 \mathrm{~km}$, and background about $30 \mathrm{~ms}$ (corresponding to $4500 \mathrm{~km}$ ) after the lidar signal. Information for a meaningful estimation of signal induced noise was not stored. Since 1999, much more information has been recorded. This has shown that signal induced noise for the DWD lidar system decays with a time constant corresponding to about $1000 \mathrm{~km}$, i.e. is almost constant on the $10 \mathrm{~km}$ time-scale of a lidar return signal. Near $100 \mathrm{~km}$, it has a typical magnitude of $3 \mathrm{~Hz}$ for the $308 \mathrm{~nm}$ signal, and $0.3 \mathrm{~Hz}$ or less for the $353 \mathrm{~nm}$ signal. This is 3 to 4 orders of magnitude smaller than in some early lidar systems that did not use a mechanical chopper (McDermid et al., 1990). Especially at $353 \mathrm{~nm}$, the uncertainty is large, because such small count-rates are buried in the statistical noise. In the improved DWD processing, background is now estimated at ranges around $100 \mathrm{~km}$, where the lidar signal is negligible, but relevant signal induced noise levels are still present.

\subsection{Ozone processing improvements}

Figure 20 shows the effect of the three corrections on ozone profiles from the DWD lidar. To correct the $\Delta z=+290 \mathrm{~m}$ altitude error found for the DWD lidar, all ozone profiles have to be shifted down by $290 \mathrm{~m}$. The required ozone correction (green line) is proportional to the ozone vertical gradient. The correction is zero near the ozone maximum at $23 \mathrm{~km}$. It is positive at altitudes below the ozone maximum (high ozone shifted down). Near $15 \mathrm{~km}$ it reaches up to $+5 \%$ on average, and up to $+15 \%$ for individual profiles (compare Fig. 6). The correction is negative above the ozone maximum (low ozone shifted down). Above $35 \mathrm{~km}$, it amounts to -5 to $-6 \%$ on average. As individual profiles become noisy above 40 to $45 \mathrm{~km}$, the correction can range between $-25 \%$ and $+15 \%$.

The effect of the differential filter bias correction is shown by the red line in Fig. 20. As mentioned, this correction is largest where the curvature (second derivative) of the ozone profile is large and the filter width is large. This is the case near $39 \mathrm{~km}$ altitude, where the correction reaches up to $15 \%$. Near $44 \mathrm{~km}$, the vertical gradient (first derivative) of the ozone profile reaches a minimum (green line), so the curvature of the ozone profile changes sign. Correspondingly, the bias correction (red line) changes from positive to negative near $44 \mathrm{~km}$. Near $19 \mathrm{~km}$, the curvature of the ozone profile is high, but the filter is quite narrow. Here the bias correction shows only a very small maximum. Above $30 \mathrm{~km}$, the bias correction increases rapidly, because filter width increases rapidly (compare Fig. 4).

The effect of the improved background subtraction (or signal induced noise correction) is shown by the light blue range in Fig. 20. It is more uncertain than the other corrections. Typically, signal induced noise is an order of 


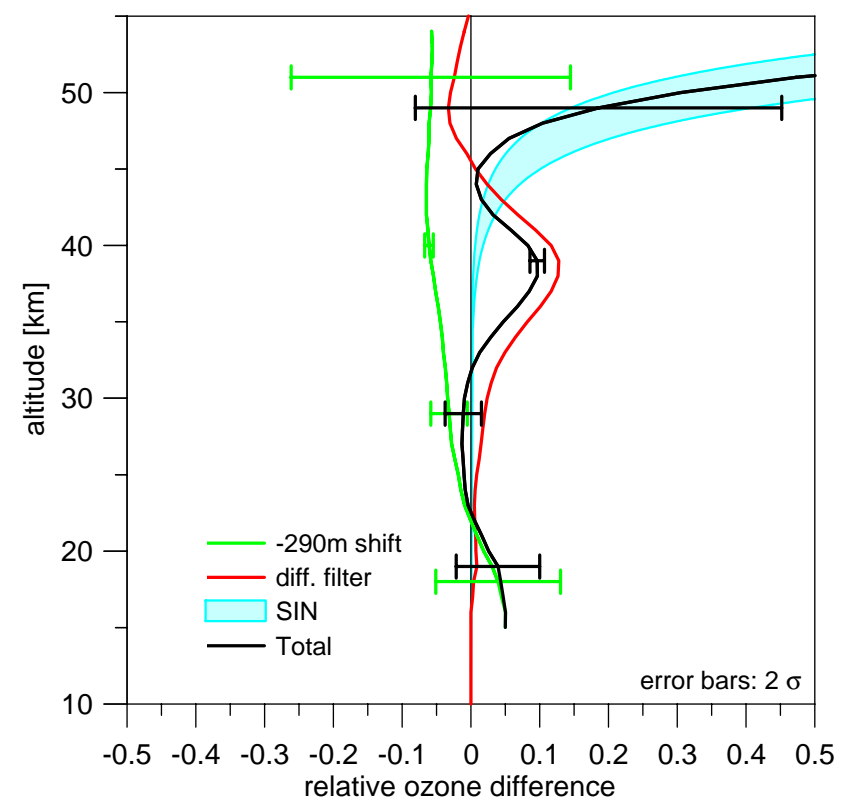

Fig. 20. Effect of different corrections in the improved ozone processing for the DWD lidar. Green: Effect of $290 \mathrm{~m}$ downward shift of the ozone profile. Error bars give the range during HOPE. Red: Effect of bias correction for the differential filter. Light blue: Range of signal induced noise correction due to improved background estimation. The given range is for typical operational measurements of the DWD lidar. The correction during HOPE was near the lower end of this range. Black line: Total effect of all three improvements. Error bars: Two standard errors.

magnitude higher at $308 \mathrm{~nm}$ than at $353 \mathrm{~nm}$. If this is ignored, the $308 \mathrm{~nm}$ lidar return signal decays more slowly than the $353 \mathrm{~nm}$ lidar return signal. The result are too low, or even negative, ozone values. An improved background estimation, therefore, results in higher ozone values. As shown by the light blue range in Fig. 20, the effect is almost negligible at altitudes below $40 \mathrm{~km}$ for the DWD lidar. However, when approaching the upper range limit of the DWD lidar near $50 \mathrm{~km}$, the signal induced noise correction increases dramatically, from around $10 \%$ near $45 \mathrm{~km}$ to around $50 \%$ near $50 \mathrm{~km}$.

Note that signal induced noise effects depend on maximum photomultiplier exposure and overall signal level. They are fairly variable. Signal induced noise effects for the DWD lidar during HOPE were closer to the lower end of the light blue area in Fig. 20. As mentioned, the NASA lidar has higher levels of signal induced noise at $308 \mathrm{~nm}$ (compare Table 1), but NASA lidar return signals are also much higher, and the NASA processing includes a good signal induced noise estimation. Still, ozone errors related to signal induced noise can reach several percent above $45 \mathrm{~km}$ for the NASA lidar as well.

The total effect of all improvements in the DWD ozone processing is given by the black line in Fig. 20. It is similar

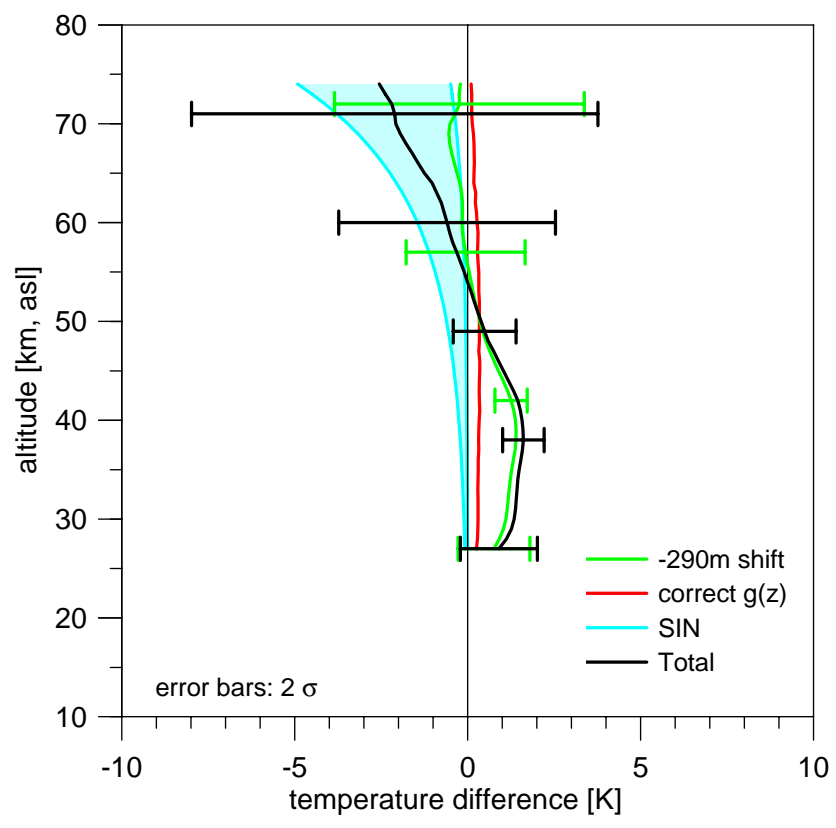

Fig. 21. Effect of different corrections in the improved temperature processing for the DWD lidar. Green: Effect of $-290 \mathrm{~m}$ range correction. This shifts the temperature profile downwards, but it also changes the $z^{2}$ range correction in the temperature calculation. Error bars give the range during HOPE. Red: Effect of corrected acceleration due to Earth's gravity, $g(z)$. Light blue: Range of signal induced noise correction due to improved background estimation. The given range is typical for operational measurements of the DWD lidar. The correction during HOPE was near the lower end of this range. Black line: Total effect of all three improvements. Error bars: Two standard errors.

to the sum of the individual effects. Below $25 \mathrm{~km}$, the total effect is largely given by the $290 \mathrm{~m}$ downward shift of the ozone profile. Between 30 and $42 \mathrm{~km}$, the total effect reaches up to $10 \%$ and is a combination of the differential filter correction and the shift. Above $45 \mathrm{~km}$, the effect of the improved background subtraction becomes dominant, and the error bars grow dramatically.

\subsection{Temperature processing improvements}

The magnitude of the different corrections in the improved temperature processing for the DWD lidar is plotted in Fig. 21. As for ozone, the $-290 \mathrm{~m}$ range correction shifts the entire temperature profile downward. In addition, however, the underlying density estimate, $n_{\text {air }}(z) \propto P(z) z^{2}$, changes as well, because the assigned $z$ has to be reduced. This results in smaller densities and higher temperatures (see also Leblanc et al., 1998). As the green line in Fig. 21 shows, the net effect of the range correction is to increase temperatures from the DWD lidar between 28 and $53 \mathrm{~km}$, by up to $1.5 \mathrm{~K}$. Above $50 \mathrm{~km}$, the vertical temperature gradient is reversed, so the effects of profile shift and reduced density almost cancel each 


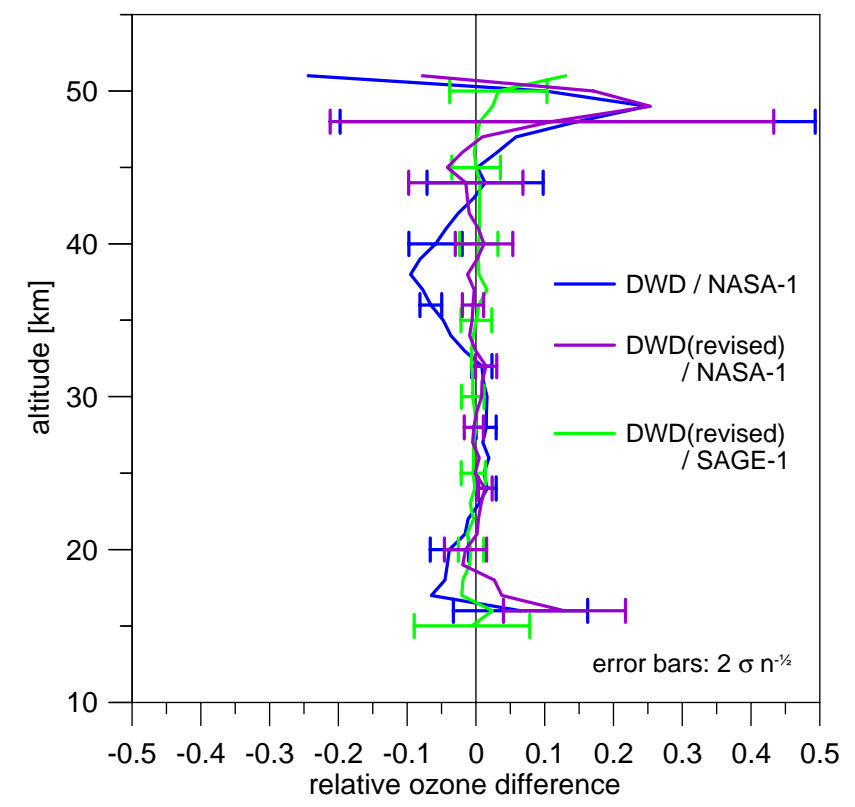

Fig. 22. Average relative ozone differences for improved processing of the DWD lidar data. Blue: Difference between original DWD processing and NASA lidar during HOPE, same as in Figs. 11 and 12. Violet: Difference between improved DWD processing and NASA lidar during HOPE. Green: Difference between improved DWD processing and SAGE ozone profiles, based on monthly mean climatology for the years 1994 to 2003. Same as DWD/SAGE-1 in Fig. 11, but with corrected DWD processing. Error bars: Two standard errors of the mean.

other. Here the net temperature change is small. As temperature profiles get increasingly noisy from 55 to $70 \mathrm{~km}$ (compare Fig. 6), error bars increase substantially.

During the investigation, it also turned out that the old DWD temperature algorithm used slightly too low values for $g(z)$, the acceleration due to Earth's gravity. $9.793 \mathrm{~m} \mathrm{~s}^{-2}$ were used for $g(0)$, instead of $9.809 \mathrm{~m} \mathrm{~s}^{-2}$, the correct value at $48^{\circ} \mathrm{N}$ (e.g., WGS, 2000, Eq. 4-1). This affects the hydrostatic equilibrium pressure calculation, and therefore the retrieved temperature. As the red line in Fig. 21 shows, using the correct $g(z)$ in the improved DWD temperature algorithm, increases temperature by about $0.3 \mathrm{~K}$ at most altitudes.

Finally, the correct estimation of signal induced noise also plays a minor role in the temperature processing (see also Leblanc et al., 1998). Although signal induced noise at $353 \mathrm{~nm}$ is an order of magnitude smaller than at $308 \mathrm{~nm}$, the light blue range indicates that the better background estimation of the improved DWD algorithm results in lower temperatures, by up to $2 \mathrm{~K}$ near $60 \mathrm{~km}$, and by up to $4 \mathrm{~K}$ near $70 \mathrm{~km}$. As mentioned, the uncertainty of the signal induced noise estimation is high. For single temperature profiles the effect is usually buried in the noise, which for the DWD lidar is about $5 \mathrm{~K}$ near $60 \mathrm{~km}$, and $10 \mathrm{~K}$ near $70 \mathrm{~km}$ (compare red line in Fig. 10). Because of its much higher return signals,

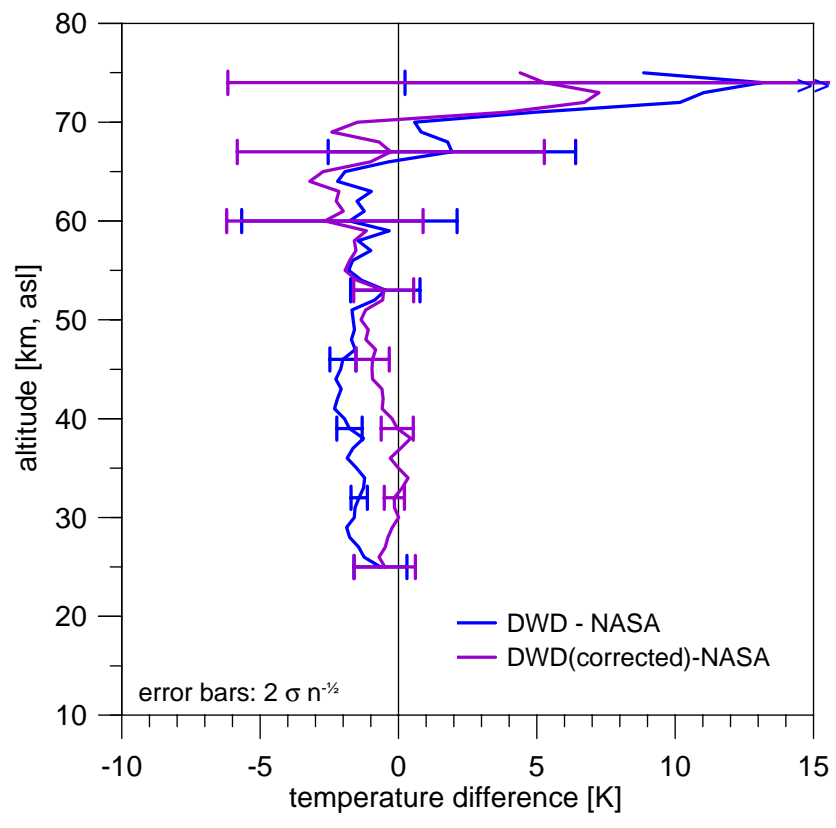

Fig. 23. Average temperature difference during HOPE. Violet: Between improved DWD lidar processing and NASA lidar. Blue: Between original DWD lidar processing and NASA lidar, same as in Figs. 13 and 14. Error bars: Two standard errors of the mean.

signal induced noise effects on temperatures from the NASA lidar are negligible.

The total temperature change due to the improved processing (black line) is again similar to the sum of the individual effects. Below $50 \mathrm{~km}$, the net effect is an increase of temperatures by up to $1.7 \mathrm{~K}$ near $40 \mathrm{~km}$. Near the upper range limit at 60 to $70 \mathrm{~km}$, the signal induced noise correction becomes large, but is also quite uncertain.

\subsection{Comparison of improved ozone and temperature profiles}

At most altitudes, below $45 \mathrm{~km}$ for ozone, and below $65 \mathrm{~km}$ for temperature, the changes due to the improved DWD ozone and temperature processing vary only a little from profile to profile. Therefore, the scatter diagrams in Sect. 4.5, as well as the standard deviations and error estimates in Sect. 4.2, largely remain valid. Significant changes, however, occur for the average differences between DWD lidar ozone and temperature profiles (Figs. 11 to 14). This can be seen in Figs. 22 and 23, which compare the uncorrected HOPE average ozone and temperature differences (blue lines), with the same results obtained for the improved DWD lidar processing (violet lines).

For ozone, the previously significant low bias in the 33 to $43 \mathrm{~km}$ altitude range (blue line) has disappeared with the new processing. Now, excellent agreement is found at most altitudes from 15 to 45 or $50 \mathrm{~km}$, both with the NASA lidar 
during HOPE (violet line), and with SAGE for the 1994 to 2003 climatological profiles (green line). Between 17 and $47 \mathrm{~km}$, systematic differences between the corrected DWD lidar ozone profiles and profiles from the NASA lidar or from SAGE are now smaller than 5\%. Between 20 and $44 \mathrm{~km}$, they are even smaller than $3 \%$. At nearly all altitudes these differences are not statistically significant. The good agreement between three different instruments in Fig. 22 does not only validate the DWD lidar ozone profiles obtained by the improved processing. It also shows excellent agreement between ozone profiles from SAGE and the NASA lidar, and gives us better confidence for using the NASA lidar as a reference standard for ozone.

The positive effects of the improved DWD temperature processing are shown in Fig. 23. With the new processing (violet line) agreement between DWD lidar and NASA lidar temperatures improves significantly between 30 and $45 \mathrm{~km}$. DWD temperatures increase by 1 to $2 \mathrm{~K}$ between 30 and $50 \mathrm{~km}$, and come into close agreement with temperatures from the NASA lidar. Except for near $45 \mathrm{~km}$ altitude, the corrected DWD temperatures now show no significant difference to the NASA data. The corrected DWD lidar temperatures also come into better agreement with sonde and NDSC temperatures (compare Figs. 13 and 14).

\section{Conclusions}

Thirteen clear nights in October 2005 have allowed the successful intercomparison of the DWD ozone and temperature lidar at Hohenpeißenberg with the NDACC travelling standard lidar operated by NASA's Goddard Space Flight Center. Additional comparison profiles were provided by Brewer/Mast ozonesondes started at Hohenpeißenberg, by Vaisala RS92 radiosondes launched at Munich $(65 \mathrm{~km}$ to the north-east), and by operational NCEP analyses.

The HOPE intercomparison confirmed a low bias for ozone profiles from the DWD lidar in the 33 to $43 \mathrm{~km}$ region, by up to $10 \%$. This bias has been seen in previous intercomparisons, e.g. against SAGE, GOMOS or GOME. It is largely caused by the differential filter used in the DWD ozone processing algorithm. The HOPE intercomparison has also been instrumental in uncovering a $290 \mathrm{~m}$ error in the range assignment of the DWD lidar. In an improved version of the DWD ozone processing, this range error is corrected, an improved differential filter is used, and a better background estimation is applied. With this improved processing, excellent agreement, better than $3 \%$ over the entire 18 to $43 \mathrm{~km}$ range, is found on average between ozone profiles from the DWD lidar, from the NASA lidar (during HOPE), and from SAGE (over the 1993 to 2004) period. This good agreement between three different systems validates not only ozone profiles from the DWD lidar, but also the NASA travelling standard lidar.
Like previous campaigns, HOPE has demonstrated that lidars deliver their best precision, better than 5\%, for ozone between 20 and $40 \mathrm{~km}$ altitude. Above $45 \mathrm{~km}$, the DWD and NASA lidar ozone data become increasingly noisy. Precision drops from around $10 \%$ near $45 \mathrm{~km}$ to $50 \%$ or worse near $50 \mathrm{~km}$. The DWD lidar compensates for its much weaker return signals by using a much coarser range resolution. Ozone variations from the two lidars track very well. Correlations are higher than 0.8 at most altitudes from 15 to $40 \mathrm{~km}$. As the ozone data become increasingly noisy above $40 \mathrm{~km}$, correlations drop to zero around $50 \mathrm{~km}$. Up to $30 \mathrm{~km}$, the ozonesondes also provide good measurements, with virtually no bias between 20 and $30 \mathrm{~km}$, and a low bias up to $5 \%$ above $30 \mathrm{~km}$. Precision of the ozonesondes is 5 to $10 \%$. Correlation between ozonesondes and lidar is in the range 0.6 to 0.9 , not quite as good as between the two lidars. In part, this might reflect the different character of the very local in-situ measurement by the sondes and the nightly mean profiles from the lidars.

Temperature data from the DWD lidar have a 1 to $2 \mathrm{~K}$ cold bias over the entire region from 30 to $65 \mathrm{~km}$ against profiles from the NASA lidar, and a 2 to $4 \mathrm{~K}$ cold bias against Vaisala RS92 radiosondes or NCEP analyses. As with ozone, the temperature bias during HOPE is consistent with multi-year intercomparisons between DWD lidar and NCEP analyses or radiosondes. The altitude shift and slightly too low $g(z)$ discovered by the detailed analysis of the HOPE data can now finally explain much of this long-standing bias. When these mistakes are corrected, the DWD temperature data come into very close agreement with the NASA data. Remaining temperature differences between the two lidars are usually less than $1 \mathrm{~K}$ between 27 and $55 \mathrm{~km}$, and are not statistically significant at most altitudes between 25 and $70 \mathrm{~km}$.

For temperature, precision of the DWD lidar is better than $2 \mathrm{~K}$ in the 30 to $50 \mathrm{~km}$ altitude range, decreasing to $10 \mathrm{~K}$ near $70 \mathrm{~km}$. The HOPE comparison has shown that the current DWD algorithm over-estimates temperature precision, because it does not account for the noise reduction obtained by averaging over 5 range bins. Estimated temperature precision values should be reduced by a factor $\sqrt{5} \approx 2.2$ (e.g. from $22 \mathrm{~K}$ to $10 \mathrm{~K}$, near $70 \mathrm{~km}$ ). The NASA lidar uses a much coarser altitude resolution for temperature, and estimates precision better than $1 \mathrm{~K}$ between 20 and $75 \mathrm{~km}$. This is very precise and could not be checked with the data available in HOPE. Between 10 and $40 \mathrm{~km}$, temperature variations are tracked very similarly by both lidars, Munich radiosondes, and NCEP analyses. Correlation coefficients are usually larger than 0.8 to 0.9 . Above $40 \mathrm{~km}$, temperatures from the three topmost levels of the NCEP analyses do not track the lidar results well ( $R$ approaches zero), whereas the two lidars show reasonable tracking $(R>0.4)$ up to $70 \mathrm{~km}$. 
Interestingly, both lidars (DWD after correction) still report slightly lower temperatures than radiosondes or NCEP analyses, by around $1 \mathrm{~K}$ over the 15 and $50 \mathrm{~km}$ altitude range. A slight cold-bias of this magnitude appears to be a very consistent result of intercomparisons between several lidars and other temperature data (see also Burris et al., 2002). Some of the bias might come from neglected effects of stratospheric aerosol. It is unlikely, however, that aerosol can explain the bias near $35 \mathrm{~km}$ altitude, and not result in an even larger bias at lower altitudes. We speculate that much of the bias may be caused by multiple scattering, presently ignored in the lidar temperature derivation according to Eq. (4). Another potential explanation, the change of effective filter transmission for radiation in the rotational Raman wings, caused by the change of the spectral shape of the return signals with the atmospheric temperature profile (She, 2001; Whiteman, 2003), can largely be ruled out: For the parameters of the NASA and DWD lidar, we have estimated related temperature errors to be small, less than $\pm 0.2 \mathrm{~K}$.

The ozone and temperature biases confirmed by the HOPE intercomparison have been present in the DWD lidar record since the beginning in 1987. Long-term comparison with ozone records from SAGE and HALOE indicates no change over time for the ozone bias (Steinbrecht et al., 2006). Comparison of the temperature record with NCEP and ECWMF re-analyses, as well as HALOE measurements, (unpublished results) indicates good long-term stability for temperature as well. To our present knowledge, the Hohenpeißenberg lidar record for ozone and temperature is internally consistent. It is suited for long-term trend analysis. HOPE, however, has been instrumental for discovering and defining several errors, that have been present for a long time. The DWD ozone and temperature algorithms have been corrected and improved. The good agreement between both lidars during HOPE, but also with the other data sources, validates not only the DWD lidar. It also confirms that the NASA lidar is an accurate travelling standard for the NDACC network. Now, the entire DWD lidar data set since 1987 needs to be re-processed and re-submitted to NDACC and other relevant data centers.

Acknowledgements. We thank S. Steiner and M. Adelwart, who carefully prepared the ozone sondes, and launched them very successfully at various times early in the morning and late at night. F. Riesemann helped to sort out odds and ends during the campaign. R. Neuber is thanked for acting as the impartial referee in the "blind" part of the intercomparison. The Hohenpeißenberg group thanks P. Newman and M. Heney for providing NCEP temperature data over many years on a daily basis. Two anonymous reviewers have provided very useful comments, and have helped to improve the manuscript.

Edited by: K. Strong

\section{References}

Braathen, G. O., Godin-Beekmann, S., Keckhut, P., McGee, T. J., Gross, M. R., Vialle, C., and Hauchecorne, A.: Intercomparison of stratospheric ozone and temperature measurements at the Observatoire de Haute Provence during the OTOIC NDSC validation campaign from 1-18 July 1997, Atmos. Chem. Phys. Discuss., 4, 5303-5344, 2004, http://www.atmos-chem-phys-discuss.net/4/5303/2004/.

Brinksma, E. J., Meijer, Y., McDermid, I. S., Cageao, R., Bergwerff, J., Swart, D. P. J., Ubachs, W., Matthews, A., Hogervorst, W., and Hovenier, J.: First lidar observations of mesospheric hydroxyl, Geophys. Res. Lett., 25, 51-54, 1998.

Burris J., McGee, T. J., Hoegy, W., Lait, L., Twigg, L. W., Sumnicht, G., Heaps, W., Hostetler, C., Bui, T. P., Neuber, R., and McDermid, I. S.: Validation of temperature measurements from the airborne Raman ozone temperature and aerosol lidar during SOLVE, J. Geophys. Res., 107(D20), 8286, doi:10.1029/2001JD001028, 2002.

Claude, H., Schönenborn, F., Steinbrecht, W., and Vandersee, W.: New evidence for ozone depletion in the upper stratosphere, Geophys. Res. Lett., 21(22), 2409-2412, 1994.

Carswell, A. I., Pal, S. R., Steinbrecht, W., Whiteway, J. A., Ulitsky, A., and Wang, T. Y.: Lidar measurements of the middle atmosphere Can. J. Phys., 69, 1076-1086, 1991.

Donovan, D. P., Whiteway, J. A., and Carswell, A. I.: Correction for nonlinear photon-counting effects in lidar systems, Appl. Opt., 32, 6742-6753, 1993.

Ferrare, R. A., McGee, T. J., Whiteman, D., Burris, J., Owens, M., Butler, J., Barnes, R. A., Schmidlin, F., Komhyr, W., Wang, P. H., McCormick, M. P., and Miller, A. J.: Lidar measurements of stratospheric temperature during STOIC, J. Geophys. Res., 100(D5), 9303-9312, 1995.

Geh, B.: Aufbau einer automatischen Apparatur zur Messung der stratosphärischen Ozonkonzentration, Diploma thesis, LudwigMaximilians Universität, Munich, Germany, 66 pp., 1987.

Godin, S., Carswell, A. I., Donovan, D. P., Claude, H., Steinbrecht, W., McDermid, I. S., McGee, T. J., Gross, M. R., Nakane, H., Swart, D. P. J., Bergwerff, H. B., and Uchino, O.: Ozone Differential Absorption Lidar Algorithm Intercomparison, Appl. Opt., 38, 6225-6236, 1999.

Gross, M. R., McGee, T. J., Ferrare, R. A., Singh, U. N., and Kimvilikani, P.: Temperature Measurements Made with a Combined Rayleigh-Mie/Raman Lidar, Appl. Opt., 24, 5987-5995, 1997.

Hauchecorne, A. and Chanin, M.-L.: Density and temperature profiles obtained by lidar between 35 and $70 \mathrm{~km}$, Geophys. Res. Lett., 7, 565-568, 1980.

Iikura, Y., Sugimoto, N., Sasano, Y., and Shimzu, H.: Improvement on lidar data processing for stratospheric aerosol measurements, Appl. Opt., 26, 5299-5306, 1987.

Keckhut, P., McDermid, I. S., Swart, D. P. J., McGee, T., GodinBeekmann, S., Adriani, A., Barnes, J., Baray, J.-L., Bencherif, H., Claude, H., di Sarra, A. G., Fiocco, G., Hansen, G., Hauchecorne, A., Leblanc, T., Lee, C. H., Pal, S., Megie, G., Nakane, H., Neuber, R., Steinbrecht, W., and Thayer, J.: Review of ozone and temperature lidar validations performed within the framework of the Network for the Detection of Stratospheric Change, J. Environ. Monit., 6, 1-14, 2004.

Leblanc, T., McDermid, I. S., Hauchecorne, A., and Keckhut, P.: Evaluation of optimization of lidar temperature analysis algo- 
rithms using simulated data. J. Geophys. Res., 103, 6177-6187, 1998.

Margitan, J. J., Barnes, R. A., Brothers, G. B., Butler, J., Burris, J., Connor, B. J., Ferrare, R. A., Kerr, J. B., Komhyr, W. D., McCormick, M. P., McDermid, I. S., McElroy, C. T., McGee, T. J., Miller, A. J., Owens, M., Parrish, A. D., Parsons, C. L., Torres, A. L., Tsou, J. J., Walsh, T. D., and Whiteman, D.: Stratospheric ozone intercomparison campaign (STOIC) 1989: Overview, J. Geophys. Res., 100(D5), 9193-9208, 1995.

McDermid, I. S., Godin, S. M., and Lindquist L. O.: Ground-based laser DIAL system for long-term measurements of stratospheric ozone, Appl. Opt., 29, 3603-3612, 1990.

McDermid, I. S., Bergwerff, J., Bodeker, G. E., Boyd, I., Brinksma, E., Connor, B., Farmer, R., Gross, M., Kimvilakani, P., Matthews, W., McGee, T., Ormel, F., Parrish, A., Singh, U., Swart, D., Tsou, J., Wang, P., and Zawodny, J.: OPAL: Network for the Detection of Stratospheric Change Ozone Profiler Assessment at Lauder, New Zealand 1. Blind intercomparison, J. Geophys. Res., 103(D22), 28683-28692, 1998a.

McDermid, I. S., Bergwerff, J., Bodeker, G. E., Boyd, I., Brinksma, E., Connor, B., Farmer, R., Gross, M., Kimvilakani, P., Matthews, W., McGee, T., Ormel, F., Parrish, A., Singh, U., Swart, D., and Tsou, J.: OPAL: Network for the detection of stratospheric change ozone profiler assessment at Lauder, New Zealand 2. Intercomparison of revised results, J. Geophys. Res., 103(D22), 28693-28700, 1998b.

McGee, T. J., Whiteman, D., Ferrare, R., Butler, J. J., and Burris, J.: STROZ LITE: Stratospheric Ozone Lidar Trailer Experiment, Opt. Eng., 30, 31-39, 1991.

McGee, T. J., Gross, M. R., Ferrare, R., Heaps, W., and Singh, U. N.: Raman DIAL measurements of stratospheric ozone in the presence of volcanic aerosols, Geophys. Res. Lett., 20, 955-958, 1993.

McGee, T. J., Gross, M. R., Singh, U. N., Butler, J. J., and Kimvilakani, P. E.: Improved stratospheric ozone lidar, Opt. Eng., 34, 1421-1430, 1995a.

McGee, T. J., Ferrare, R. A., Whiteman, D., Butler, J. J., Burris, J. F., and Owens, M. A.: Lidar measurements of stratospheric ozone during the STOIC campaign, J. Geophys. Res., 100(D5), 9255-9262, 1995b.

McGee, T. J., Gross, M. R., Singh, U. N., Kimvilakani, P., Matthews, A., Bodeker, G., Connor, B., Tsou, J. J., Proffitt, M., and Margitan, J.: Vertical profile measurements of ozone at Lauder, New Zealand during ASHOE/MAESA, J. Geophys. Res., 102(D11), 13283-13290, 1997.

McPeters, R. D., Hofmann, D., Clark, M., Flynn, L., Froidevaux, L., Gross, M., Johnson, B., Koenig, G., Liu, X., McDermid, I. S., McGee, T., Murcray, F., Newchurch, M.J., Oltmans, S., Parrish, A., Schnell, R., Singh, U., Tsou, J. J., Walsh, T., and Zawodny, J. M.: Results from the 1995 stratospheric ozone profile intercomparison at Mauna Loa, J. Geophys. Res., 104(D23), 30505-30514, 1999.

Meijer, Y. J., Swart, D. P. J., Allaart, M., Andersen, S. B., Bodeker, G., Boyd, I., Braathen, G., Calisesi, Y., Claude, H., Dorokhov, V., von der Gathen, P., Gil, M., Godin-Beekmann, S., Goutail, F., Hansen, G., Karpetchko, A., Keckhut, P., Kelder, H. M., Koelemeijer, R., Kois, B., Koopman, R. M., Kopp, G., Lambert, J.C., Leblanc, T., McDermid, I. S., Pal, S., Schets, H., Stubi, R., Suortti, T., Visconti, G., and Yela, M.: Pole-to-pole valida- tion of Envisat GOMOS ozone profiles using data from groundbased and balloon sonde measurements, J. Geophys. Res., 109, D23305, doi:10.1029/2004JD004834, 2004.

Megie, G. J., Ancellet, G., and Pelon, J.: Lidar measurements of ozone vertical profiles, Appl. Opt., 24, 3454-3463, 1985.

Press, W. H., Teukolsky, S. A., Vetterling, W. T., and Flannery, B. P.: Numerical Recipes in C, Cambridge University Press, Cambridge, UK, 994 pp., 1992.

Rees, D., Barnett, J. J., and Labitzke, K. (Eds.): COSPAR International reference atmosphere: 1986 Part II: Middle Atmosphere Models, Pergamon Press, Oxford, UK, 519 pp., 1990.

She, C.-Y.: Spectral structure of laser light scattering revisited: bandwidths of nonresonant scattering lidars, Appl. Opt., 40, 4875-4884, 2001.

Sica, R. J., Zylawy, Z. A., and Argall, P. S.: Ozone corrections for Rayleigh-scatter temperature determinations in the Middle Atmosphere, J. Atmos. Ocean. Tech., 18, 1223-1228, 2001.

Singh, U. N., Keckhut, P., McGee, T. J., Gross, M. R., Hauchecorne, A., Fishbein, E. F., Waters, J. W., Gille, J. C. Roche, A. E., and Russell, J. M. III: Stratospheric temperature measurements by two collocated NDSC lidars during UARS validation campaign, J. Geophys. Res., 101(D6), 10287-10297, 1996.

Smit, H. G. J and Kley, D.: JOSIE: The 1996 WMO International intercomparison of ozonesondes under quasi flight conditions in the environmental simulation chamber at Jülich, WMO GAW report No. 130, WMO-TD No. 926, World Meteorological Organization, Geneva, (available from http://www.fz-juelich.de/icg/ icg-2/josie/1996/), 108 pp., 1998.

Steinbrecht, W., Rothe, K. W., and Walther, H.: Lidar setup for daytime and nighttime probing of stratospheric ozone and measurements in polar and equatorial regions, Appl. Opt., 28, 36163624, 1989.

Steinbrecht, W.: Lidar measurements of ozone, aerosol, and temperature, $\mathrm{PhD}$ thesis, York University, Toronto, Canada, 250 pp., 1994.

Steinbrecht, W. and Carswell, A. I.: Evaluation of the effects of Mount Pinatubo aerosol on differential absorption lidar measurements of stratospheric ozone, J. Geophys. Res., 100(D1), 12151234, 1995.

Steinbrecht, W., Winkler, P., and Claude, H.: Ozon- und Temperaturmessungen mittels Lidar am Hohenpeißenberg. Rep. No. 200, Deutscher Wetterdienst, Offenbach, Germany, available at: http://www.dwd.de/bvbw/generator/ Sites/DWDWWW/Content/Forschung/FEHP/MOHP/DL/ PUBLIKATION/o__dwd200__de__pdf, 89 pp.1997.

Steinbrecht, W., Schwarz, R., and Claude, H.: New Pump Correction for the Brewer-Mast Ozone Sonde: Determination from Experiment and Instrument Intercomparisons, J. Atmos. Ocean. Tech., 15, 144-156, 1998.

Steinbrecht W., Claude, H., Schönenborn, F., McDermid, I.S., Leblanc, T., Godin, S., Song, T., Swart, D. P. J., Meijer, Y. J., Bodeker, G. E., Connor, J., Kämpfer, N., Hocke, K., Calisesi, Y., Schneider, N., de la Noë, J., Parrish, A. D., Boyd, I. S., Brühl, C., Steil, B., Giorgetta, M. A., Manzini, E., Thomason, L. W., Zawodny, J. M., McCormick, M. P., Russell III, J. M., Bhartia, P. K., Stolarski, R. S., and Hollandsworth-Frith, S. M.: Longterm evolution of upper stratospheric ozone at selected stations of the Network for the Detection of Stratospheric Change (NDSC), J. Geophys. Res., 111, D10308, doi:10.1029/2005JD006454, 
2006.

Steinbrecht W., Claude, H., Schönenborn, F., Leiterer, U., Dier, H., and Lanzinger, E.: Pressure and Temperature Differences between Vaisala RS80 and RS92 Radiosonde-Systems J. Atmos. Ocean. Tech., 25, 909-927, doi:10.1175/2007JTECHA999.1, 2008.

Tsou, J. J., Connor, B. J., Parrish, A., Pierce, R. B., Boyd, I. S., Bodeker, G. E., Chu, W. P., Russell III, J.M., Swart, D. P. J., and McGee, T. J.: NDSC millimeter wave ozone observations at Lauder, New Zealand, 1992-1998: Improved methodology, validation, and variation study, J. Geophys. Res., 105(D19), 24263 24281, 2000.

Werner J., Rothe, K. W., and Walther, H.: Monitoring of the stratospheric ozone layer by laser radar, Appl. Phys., B32, 113-118, 1983.
Whiteman, D. N.: Examination of the traditional Raman lidar technique. I. Evaluating the temperature-dependent lidar equations, Appl. Opt., 42, 2571-2592, 2003.

Williamson, C. K. and De Young, R. J.: Method for the reduction of signal-induced noise in photomultiplier tubes, Appl. Opt., 39, 1973-1979, 2000.

WGS84: Department of Defense World Geodetic System 1984, Report 8350.2, 3rd edition, US National Imagery and Mapping Agency, Bethesda, Maryland, available at: http://earth-info.nga. mil/GandG/wgs84/, 175 pp., 2000. 